\title{
Waving Goodbye? The Determinants of Autonomism and Secessionism in Western Europe
}

\author{
Brais Álvarez Pereira*, Martín Portos ${ }^{\dagger}$ and John Vourdas ${ }^{\ddagger}$
}

October 17, 2017

\begin{abstract}
This paper sheds light on the main aggregate-level determinants of electoral support for regionalist parties across 10 Western European countries. A region being relatively richer than the country to which it belongs is associated with higher electoral support for regionalist parties only to the extent that the region is culturally differentiated. This hypothesis is substantiated theoretically, tested empirically and found to hold in the form of a strong and significant interaction effect between cultural and economic variables. This result, omitted in previous studies, implies a profound change in the interpretation of the role of income and cultural differences in explaining support for regionalism, for both autonomist and separatist parties.
\end{abstract}

Keywords: secessionism, autonomism, Western Europe, cultural distance, electoral behaviour

${ }^{*}$ Department of Economics, European University Institute, 50133 Florence, Italy. e-mail: brais.alvarespereira@gmail.com

$\dagger$ Department of Political and Social Sciences, European University Institute and COSMOS \& Institute of Humanities and Social Science Research Centre, Florence, Italy

${ }_{\ddagger}^{\ddagger}$ Department of Economics, European University Institute, Florence, Italy 


\section{Introduction}

The study of the determinants of the break-up of countries and the origin of new nation-states received considerable attention following the collapse of the Soviet Union and Yugoslavia. ${ }^{1}$ Recently, this topic has regained momentum as two large regions have been pushing for their independence. ${ }^{2}$ In Scotland the Scottish $\mathrm{Na}$ tional Party-led Government held a referendum on independence from the UK in September 2014. Despite the unionist win, a sizable proportion of $44.7 \%$ of voters opted for secession (turnout: 84.59\%). Likewise, Catalan authorities strove to hold an official plebiscite on independence, but faced outright opposition from the Spanish Government and the Constitutional Court. Given these circumstances, a large-scale non-binding unofficial voting performance led by civil society organizations took place instead, with the collaboration of the Catalan regional Government. In total, over 2.3 million votes were cast in November 2014 (estimated turnout was approximately $40 \%$ ), with $80.8 \%$ of participants ticking the 'yes-yes' option (i.e. yes, for a state for Catalonia; yes, for an independent state)(Della Porta et al., 2017).

While these are arguably two extreme cases, support for greater regional ${ }^{3}$ autonomy has been rising within EU member states, against a backdrop of the wider European integration process between member states. However, electoral research tends to overlook the relevance of the center-periphery axis on vote choice (Medeiros et al. 2015).

In line with the most recent literature, we will refer to regionalism as the process of agitation within a sub-state territorial unit or region that leads to increasing demands for greater autonomy, which seeks to recognize, empower, and reinforce its structure of self-government (De Winter et al. 1998; Massetti 2009). Within regionalist parties, we define a party as autonomist if it does not intend to secede in any way from the current state, it respects the unity of the current state, and simply has an ambition for a larger degree of regional self-government (Massetti and Schakel 2016: 5, 13; Jolly 2006). A party is secessionist if it promotes a territorial subunit's detachment from the nation-state of which it is currently part, and advocates for the right to self-determination, either by becoming an independent state or by building a new one together with other territorial units (Sorens 2005, 2008, 2012). Consequently, we include irredentist parties as a subcategory of secessionist parties. Hence, regionalism embeds both autonomism and secessionism, with the latter being

\footnotetext{
${ }^{1}$ Nation-states combine the state as a system of political action with national identity, the community's entitlement to claim for self-rule (Keating 2004).

${ }^{2}$ In the vast majority of cases, secessionism demands take the form of separatism, oriented to supplying regions with independent state structures. There are exceptions, however, as people in some regions would rather prefer to join another state. For instance, the German-speaking community in the Italian South Tyrol may prefer a reattachment to Austria instead of forming a state on their own. This phenomenon is known as irredentism, which is frequently considered a specific sub-type of secessionism (Sorens 2005: 308, Sorens 2008: 339-340).

${ }^{3} \mathrm{~A}$ region is a 'territorial body of public law established at the level immediately below that of the state and endowed with political self-government' (Assembly of European Regions 1996; Hooghe et al. 2010). We use regions and territorial sub-units interchangeably throughout. A nation is defined as a community of people with a set of coordinated beliefs about their cultural identities that claim self-government, with varying degrees of intensity (Moreno 1995: 237; Laitin 2007: 40- 41).
} 
a more radical form of regionalism and the former a milder form.

Despite the rise of regionalist parties and movements in the last decades (in France, Spain, Italy and the UK, amongst others), there have been surprisingly few empirical studies on the determinants of their support. Even though there are some notable exceptions to this trend (eg., Sorens, 2005, 2008, 2012; Massetti and Schakel, 2016; Brancati, 2014), we consider that two crucial issues warrant further study, as there is no consensus about them in existing literature. Firstly, what is the relation between cultural and economic factors in explaining the electoral success of different regionalist forces? Secondly, what is the connection between the two main forms of regionalism, i.e. autonomism and secessionism? Are they two different versions of the same phenomenon or two distinct phenomena?

We argue that cultural proximity accounts for the support for increasing regional autonomy through an interaction between cultural and income-related variables which has not been explored in the existing literature. The main finding is that a region being richer relative to the rest of the country is only correlated with support for more regional autonomy if its culture is significantly different from the main one in the country, and not otherwise. Similarly, the cultural-identity gap is significantly more important in accounting for the success of regionalist and secessionist parties in relatively rich regions, playing a much smaller role in poorer ones. This common feature underpins both autonomist and secessionist electoral support. Finally, the paper develops the idea that — at least in electoral studies - these two forms of regionalism are intimately intertwined, both on theoretical and empirical grounds.

The paper is structured as follows. The next section reviews the relevant contributions in the literature. The third section develops our theoretical framework. The data, empirical model and main results from the empirical enquiry are described in the fourth section. The fifth section concludes by highlighting the main implications of this paper.

\section{Literature review}

The main factors identified in the literature as accounting for regionalist supporteither in its autonomist or secessionist versions - can be divided in two broad categories: cultural and economic (Brancati, 2014; Hooghe et al., 2010; Jolly, 2006; Massetti and Schakel, 2016; Sorens, 2005, 2008, 2012).

Cultural explanations of support for greater regional autonomy emphasize the role of historical, traditional, linguistic and ethnic factors. These are often associated with some distinctive identity features, such as having a specific minority language (Van Houten, 2000; Fearon and Van Houten, 2002). ${ }^{4}$ For example, cultural explanations help to explain the support for secessionism in Catalonia and the Basque

\footnotetext{
${ }^{4}$ National identity is the sense of a nation as a cohesive whole. It refers to the set of tendencies and values derived from the feeling of belonging to a united group of people with distinctive traditions, history and culture. National identity is neither fixed nor alterable at will. It requires a periodical redefinition in the light of historical features, present needs and future aspirations Parekh 1995 remarks.
} 
Country. These two regions have a strong tradition of identity nationalism linked to their language, and in both regions secessionist parties gathered approximately $60 \%$ of the votes in the last regional elections. ${ }^{5}$ However, Catalan is also spoken in the regions of Valencia and the Balearic Islands, which are both autonomous communities that have traditionally shown active hostility to secessionism, although there has been some, rather mild, support for autonomism (Riera, 2014). ${ }^{6}$ Similarly, while Scottish separatism has been on the rise in the last decades, Scottish Gaelic is barely spoken by $1 \%$ of Scots. This contrasts with the situation in Wales, where around $20 \%$ of the population speaks Welsh, but support for secessionism is much lower. Having a distinctive minority language might not be the only (or even the main) sign of cultural difference. Other cultural or identity aspects might play a role in determining support for greater regional autonomy. In fact, Desmet et al. 2011 show that physical distance between the capitals of two countries is a better proxy for cultural difference than the linguistic distance between their main languages. Yet, cultural factors alone cannot explain support for greater regional autonomy. We argue that cases of culturally differentiated, but relatively poor, regions, such as Galicia in Spain, Sicily in Italy or the French overseas departments, where the support for regionalism is relatively low or non-existent, show that cultural-identity factors alone cannot explain a large support for autonomist or secessionist parties.

It is well known that economic variables such as income, wealth and relative economic well-being may also influence secessionist and autonomist support. Appeals to primordial past, history and traditions of a nation seem to affect voting to a much lesser extent than material concerns and socio-economic issues, at least when it comes to endorsing secessionist parties (Sorens, 2005). Accordingly, debates on territorial separation (and also current prosecessionist referendum campaigns, such as the recent Scottish and Catalan ones) have often focused on the economic efficiency losses and gains of separation vis-à-vis the status quo. ${ }^{7}$ From an individual level of analysis, political economists have addressed this issue as well. The established literature on the break-up of nation-states, for instance, offers a trade-off that determines whether or not secession is optimal for a given individual (e.g., Alesina and Spolaore, 1997). While integration facilitates coordination and minimizes the duplication of fixed costs in the provision of public goods (e.g., in defence and law enforcement), the main incentive for independence is that the benefits from remaining united are generally not evenly distributed among all citizens (nor regions) at the country level. For instance, heterogeneity in tax contributions across regions, resulting from differences in average income per capita, accentuate economic grievances (Bolton and Roland, 1997). The latter are at the core of claims for greater autonomy and secession: the argument is that the centre's economic policies are holding the growth of the region down or that the (richer) region is subsidizing poorer ones (Horowitz, 1981). The Italian Lega Nord political party often puts these arguments forward, for example. There seems to be a widespread agreement in the literature

\footnotetext{
${ }^{5}$ Considering the following parties as secessionists: CiU, ERC, ICV, CUP and SI in Catalonia; and PNV and Bildu in the Basque Country (Nordsieck, 2015) (see table 7 in appendix 6.2).

${ }^{6}$ The Basque language is also spoken in Navarre, where there is indeed a relatively high support for both autonomist and secessionist parties.

${ }^{7}$ Muñoz and Tormos 2015 emphasize the importance of economic aspirations and partisanship in their inquiry on individual-level determinants for secessionism in Catalonia.
} 
that richer regions tend to be more prone to back autonomist (De Winter et al., 1998; Van Houten, 2000; Gordin, 2001) and secessionist parties (Sorens, 2005).

Some existing contributions have already considered the interrelated effect of both cultural and economic variables to explain secessionist support. For example, in their study on the trade-offs between the benefits of large jurisdictions and the costs of heterogeneity of large and diverse populations, Alesina and Spolaore 1997 present a model that implies that democratization leads to secessions, there is an inefficiently high number of countries in equilibrium, and the equilibrium number of countries increases in the amount of economic integration. In his study of ethnic conflict in Eurasia, Hale 2008 finds an association between ethnic distinctiveness and separatism that he contends is because ethnicity accentuates difficulties of union governments at portraying themselves as non-exploiters of minority groups on the benefit of the dominant group. Focusing on Yugoslavia, Desmet et al. 2011 find that agents' preferences over different geographical configurations (i.e. the likelihood of secessions and unions) is determined by trade-off between the costs of greater cultural heterogeneity and increasing returns in the provision of public goods.

Whilst these contributions are enlightening and advance theories to an, arguably limited, extent consistent with our main argument (i.e., economy and culture interact to promote greater support for autonomism and secessionism), this is, to the best of our knowledge, the first empirical paper with aggregated panel data that focuses on unravelling the crucial interaction effect between cultural and economic variables in explaining the support for autonomist and secessionist parties. This points not only towards an inadequacy of additive models to test for the determinants of regionalist support, but also a potential lack of theorization on the interplay between economic and cultural arguments as explanatory factors.

Another important question refers to the connection between autonomism and secessionism. It is widely accepted that these two processes are interrelated in conceptual and empirical terms (e.g. Jolly, 2006). They share many crucial aspects, as both reject and react against the status quo in favour of some alternative involving more self-government. However, some studies have stressed their diverging features (Sorens, 2008). From this point of view, autonomism and separatism would be different processes, driven by different dynamics and factors. Existing empirical evidence suggests that cultural variables are most important in determining autonomist support (Gordin, 2001; Fearon and Van Houten, 2002), whereas economic variables are most important in determining secessionist support (Sorens, 2005; Brancati, 2014). We argue that both cultural and economic factors and, most importantly, their interaction drive the electoral support for both autonomist and secessionist parties in the same direction. This, together with other empirical findings, suggests that, at least in electoral studies, autonomism and secessionism should be considered as two varieties of the same process, namely regionalism. 


\section{Theoretical framework}

\subsection{Cultural proximity, relative income, and electoral sup- port for regionalism}

Cultural proximity influences the feeling of belonging to a large social group and determines whom people in a given region region care about. This has an important role in the political participation process. When choosing whether or not to support greater regional autonomy, people whose region's culture is distinct from the majority of the nation will care more about the implications of that decision for the population in that same territorial subunit. On the other extreme, in regions whose culture mainly coincides with the main one in the country, people will tend to care relatively more about the effects that a certain political choice would have for the overall population in the country as a whole. In this context, this gap between the regional and the majoritarian culture in the country is known as cultural distance.

This effect of culture on electoral support for regional autonomy has important implications, as it introduces an important interaction between economic and cultural factors. With people in more differentiated regions caring mainly about the wellbeing of those in their same region, support for regionalism among the population will be large if this is thought to improve the situation of the full group, provided that the region is rich. Alternatively, the population in a relatively rich region will support regionalism to a large degree only when the region's culture is significantly different from the predominant one in the country. Those in highly differentiated but poor regions will tend to see the less decentralized status quo as better for their region's material interests, and we would expect a relatively low proportion of the electorate to support increasing regionalism. This analysis brings us to the main hypothesis of the paper:

Hypothesis 1: There exists a positive interaction effect between cultural and economic factors on the support for increasing regional autonomy.

This interaction between economic and cultural aspects underpinning the vote for regionalist parties has been overlooked in the literature to date, as existing aggregate studies are based on additive models. This interaction has important implications, both to explain the support for regionalist parties and to contribute to a better understanding of the determinants of the relationship between the electoral support for secessionist and for autonomist options.

\subsection{Cultural proximity, autonomism and secessionism}

The interrelationship between secessionism and autonomism warrants further analysis. From a theoretical point of view, we approach this puzzle using a simple model that builds on Sorens 2004 contribution. Voters are located on a continuum ranging from 0 to 6 , with 0 representing maximum unionism and 6 representing independence. We assume that the election is regional (and not a referendum), and we care about any voter $i$, not necessarily the median voter. Let us assume, for simplicity, 
that there are only two parties in the election, a centralist one and a regionalist one, with proposed policies respectively being $P_{c}$ and $P_{r}$. Voter $i$ preferences are given by the negative loss function:

$$
U\left(P_{j}, I_{i}\right)=-a\left(\left|P_{j}-I_{i}\right|\right)^{2}
$$

where $a$ is a positive constant, $U\left(P_{j}, I_{i}\right)$ is the utility of voter $i$ under policy $P_{j}$ and $I_{i}$ is the ideal policy point of voter $i$. In our example, the policy offered by the centralist party is $P_{c}=1$, and voter $i$ preferred policy point $I_{i}=4$. If the regionalist party is either an autonomist party with $P_{r}=3$, or a secessionist party with $P_{r}=6$, voter $i$ will choose to vote for the regionalist party (one of the two existing in this region). This is consistent with the fact that not necessarily all the people who vote for secessionist parties in a regional election want their region to break away from their current nation-state. Similarly, in regions without secessionist parties, a part of the electorate of autonomists parties might want the region to secede. This misalignment between the preferred level of regional autonomy and voting behaviour derives from the existence of a discrete number of parties, and raises the following question: should the determinants of autonomism and secessionism through electoral results be studied as two different processes or as two aspects of the same phenomena?

We argue that analyzing electoral support for these two options as different processes might lead to misleading conclusions. If secessionist parties are included in the group of 'non-autonomist parties' when empirically analyzing the determinants of electoral support for autonomist parties, the results might be biased (see Figure 2 in appendix 6.3 in the supplemental data online). As a given predictor might have an effect not only on autonomism but also on the support for secessionist parties, considering only autonomist parties as an independent category biases the estimated effect of this variable downwards. Alternatively, if support for autonomist parties is put together with non-regionalists when studying support for secessionist parties, the estimate will be biased.

In order to test this, we split the full sample into two separate ones. The first of these keeps only those regions and periods that have only votes for secessionist and nonregionalist parties, or for non-regionalist parties alone. The second contains those observations in which there is a positive proportion of votes either for autonomist and non-regionalist parties, or for just non-regionalist parties. The observations for those regions that have a positive amount of votes for the two different categories of regionalist parties are excluded in both samples, i.e., regions with support for autonomist parties are excluded from the first sample and observations with support for secessionist parties are dropped in the second one. Given that we argue the same mechanism underlies electoral support for autonomist and secessionist parties, we would expect the following hypotheses to hold:

Hypothesis 2a: For the models explaining electoral support for either autonomist or secessionist parties, the coefficients for the same variables across models (with full and the separated samples) should show statistically different results.

Hypothesis 2b: When only the separated samples are considered, coefficients ex- 
plaining support for autonomism and secessionism should not differ in statistical terms.

If hypotheses $2 \mathrm{a} / 2 \mathrm{~b}$ are satisfied, placing secessionism and autonomism in the same continuum measuring different degrees of regionalism will be justified, with maximal unionism and secessionism located at the extremes, and autonomism in between. As both increasing regional autonomy and secessionism imply steering policies to be more regional specific, we would expect the effect of the interaction between economic and cultural variables to go in the same direction - albeit not necessarily with the same intensity - for the two forms of regionalism. This gives the third hypothesis of the paper:

Hypothesis 3: The interaction effect between cultural and economic variables is positive in models explaining the electoral support for both autonomism and secessionism separately.

Confirming this hypothesis (with the separated samples) is consistent with the view of secessionism and autonomism as two forms of minority nationalism.

\section{Empirics}

\subsection{Data}

We built a cross-sectional data set using data from regions of Portugal, Spain, France, the UK, Italy, Germany, Belgium, the Netherlands, Denmark and Austria (NUTS-1 regions for Germany, Belgium, Denmark and the UK; NUTS-2 for the other cases; see table 6, in appendix 6.2).

We then merged it with the 1969-2000 data set from Sorens 2005, updating this with the most recent elections - till 2014-, and adding some explanatory variables and regions. ${ }^{8}$ Our analysis was restricted to West European countries for two reasons. Firstly, they all have established and comparable regional elections. Secondly, while cultural differences are highly correlated with geographical distances across Western Europe (Desmet et al., 2011), this is arguably not the case in countries that were settlement colonies in the past. By reducing the sample to Western Europe, we can confidently use geographical distance as a proxy for cultural differences.

The dependent variables are respectively given by the percentage of votes for autonomist ( $v \_$auton), secessionist $\left(v \_s e c\right)$, and the sum of both types of parties $\left(v \_r e g\right)$ in a given regional election. ${ }^{9}$ As the centre-periphery territorial cleavage

\footnotetext{
${ }^{8}$ We exclude Dutch, British and French overseas countries and territories (and also the Channels Islands and Isle of Man). The same holds for Greenland (Denmark), given its quasi-independent status. In turn, we include outermost regions (Azores, Madeira, Canary Islands, French overseas departments). We also consider the following 'special cases': Ceuta and Melilla (Spain), Gibraltar (UK) and Faroe Islands (Denmark).

${ }^{9}$ Our data for the percentage of votes casted for a party come both from Nordsieck 2015 Parties and Elections database and official regional or state-level resources. When more than one party fits in the secessionist or autonomist category, we aggregate their percentages. To be included, the party must have gained either seats in the regional chamber or more than $1 \%$ of votes.
} 
tends to be channelled through the institutional domain in well-established democracies, these are used as proxies for general support for each of these political options.

To determine under which category a given party falls, we use different secondary and primary sources (manifestos, party websites and various academic contributions). Our party classification fits Nordsieck 2015 recent categorization for that respective election (see 7, appendix 6.2). ${ }^{10}$ For instance, the autonomist Partido Regionalista de Cantabria is in favour of greater regional autonomy for Cantabria but not independence from Spain, whereas the Scottish SNP is characterized as secessionist because it campaigns on a platform seeking independence from the UK. ${ }^{11}$

Our two main groups of explanatory factors, cultural proximity and economic aspects, are operationalized through different predictors, as follows.

\section{Cultural variables}

- Language is the proportion of residents in the region who speak a language other than the predominant one in the country. Having a regional vernacular language strengthens the regional cultural identity. ${ }^{12}$ Aiming at protecting it, citizens may be keener to vote for regionalist parties (data sources: Lewis and Gary 2013; Sorens 2005). ${ }^{13}$

- Distance is the straight-line physical distance between the capitals of the region and the country, measured in hundreds of kilometres. In Western Europe, physical distance has historically been an obstacle to ensuring political coordination, cultural homogenization and reinforcing a sense of belonging. As Desmet et al. 2011 show using World Value Survey (WVS) data, the correlation between cultural distance and geographic distance is high (0.52) between West European countries. ${ }^{14}$ As a proxy for cultural distance, we expect distance to be positively correlated with a region's desire for greater regionalism - and the effect should be larger for relatively rich regions.

A concern is whether distance might affect $v \_r e g$ significantly through alternative channels, other than cultural. As abovementioned, using geographical distance as a proxy for cultural distance would be problematic for the whole world, particularly for former settlement colonies (e.g., United States, Canada, Australia). We test for

\footnotetext{
${ }^{10}$ Following Massetti and Schakel 2016 criteria, in electoral coalitions where regionalist parties are involved, seat allocation is used to assign vote shares to the coalition partners.

${ }^{11}$ In some cases, it can be challenging to classify political parties. For example, it is not clear to which extent the Bavarian CSU, Northern Irish UUP and Navarra's UPN act separately from statewide parties (Massetti and Schakel, 2016). We rely on Nordsieck 2015 and Sorens 2005 criteria, and considered the party as regionalist or not depending on the election. Excluding these problematic cases does not change our findings.

${ }^{12}$ This refers to long-term established regional languages, excluding recent linguistic minorities (e.g., first generations of migrants).

${ }^{13}$ Estimating the proportion of speakers and defining the linguistic status (i.e. whether it is a dialect or a language) is often problematic. Although language is time-invariant, it should be a good proxy for cultural heterogeneity.

${ }^{14}$ The correlation holds if the analysis by Desmet et al. 2011 is restricted to the countries in our sample (0.44). It is always higher than the correlation between linguistic and cultural distance: 0.42 in their sample, 0.33 for ours.
} 
the effect of distance on $v \_r e g$ in these three large former colonies. The coefficient for this variable and the interaction distance_GDP (where GDP refers to gross domestic product ratio) are not significant in any of the regressions, pointing towards alternative channels through which geographic distance could affect electoral support for regionalist parties not being particularly relevant. ${ }^{15}$ As an alternative test, we run a two-stage least squares (2SLS) model to explain $v \_r e g$, instrumenting distance and its interaction distance_GDP with language and its interaction language_GDP. Both variables are positive and statistically significant (see table 11, appendix 6.2). ${ }^{16}$

\subsubsection{Economic variables}

- GDP_ratio measures the relative difference in the average income between the region and the whole country (regional GDPpc/ national GDPpc). We centre this variable around 1 , such that it takes the value 0 when the GDP per capita of the region and that of the country are equal, and positive (negative) if the GDP per capita of the region is larger (smaller) than that of the nation as a whole. ${ }^{17}$ We expect a positive effect for this variable through its interaction with cultural distance (with positive coefficients for the interactions distance_GDP and language_GDP): richer regions will support greater autonomy and secession to avoid redistribution to poorer regions when cultural distance is larger.

- Richer_neighbor is a dummy that captures whether the region has a border with another country that is richer than the country to which it belongs, as this is associated with positive economic expectations toward independence or greater autonomy.

We also include different control variables in our models, as follows.

\section{Main controls:}

- As support for greater regional autonomy might have increased over time, year captures the year when the election took place.

- Has_neighbor is a dummy (taking the value 1 if the region has a border with another country and 0 otherwise) to isolate the effect of richer_neighbor from the general effect of having a neighbor.

- Population: The number of the region's inhabitants, in hundreds of thousands. The impact of having a larger population on the desire for greater autonomy and secession is ambiguous. More populated regions tend to have more weight on countrywide political decisions, which should decrease the support for in-

\footnotetext{
${ }^{15}$ We run a pooled ordinary least squares (OLS) regression with Sorens 2005 panel sub-sample for these three countries $(\mathrm{N}=1,000)$. As expected, while distance and the other related variables are never significant, language is still significant.

${ }^{16}$ The hypothesis of weak instrument is rejected (in model $4, F$-test for excluded instruments is $\mathrm{F}(2,120)=6.23, p=0.0027$, for distance, and 4.08, $p=0.0194$, for distance_GDP $)$.

${ }^{17}$ Given that no observation in our sample gets close to a 0 value for $G D P$ ratio, centering this variable around 1 is more appropriate (the lowest value in our sample is 0.4 ; observations below 0.6 are rare).
} 


\begin{tabular}{|l|ccccc|}
\hline Variable & \multirow{2}{*}{$\mathrm{N}$} & Mean & Std. Deviation & Min & Max \\
& & & & & \\
\hline \hline GDP_ratio & 1232 & -0.041 & 0.222 & -0.597 & 1.197 \\
\hline distance & 1309 & 3.240 & 5.159 & 0 & 93.755 \\
\hline language & 1309 & 0.142 & 0.241 & 0 & 1 \\
\hline distance_GDP & 1232 & -0.279 & 2.263 & -40.144 & 15.739 \\
\hline language_GDP & 1232 & -0.009 & 0.082 & -0.408 & 0.443 \\
\hline year & 1309 & 1990.937 & 9.243 & 1969 & 2014 \\
\hline has_neighbor & 1309 & 0.503 & 0.500 & 0 & 1 \\
\hline neighbor_richer & 1309 & 0.254 & 0.435 & 0 & 1 \\
\hline population & 1269 & 25.555 & 39.533 & 0.298 & 492.71 \\
\hline regional_elect & 1309 & 0.415 & 0.493 & 0 & 1 \\
\hline chamber_size & 1179 & 67.256 & 39.489 & 2 & 237 \\
\hline ENERP* & 1073 & 3.673 & 1.400 & 0.529 & 10.721 \\
\hline hist_together* & 1173 & 0.559 & 0.490 & 0 & 1 \\
\hline region_auton* & 1309 & 2.183 & 1.239 & 0 & 4 \\
\hline irredentist_potential & 1309 & 0.112 & 0.315 & 0 & 1 \\
\hline party_elsewhere* & 1309 & 0.133 & 0.339 & 0 & 1 \\
\hline
\end{tabular}

Table 1 - Descriptive statistics. The variables with * are only used in robustness checks.

creasing regional autonomy. However, large populated regions are more viable as independent states, which should increase the support for secessionism.

- Chamber_size measures the number of seats in the regional parliament, and is positively associated with multipartism.

- Regional_elect is a dummy that distinguishes the nature of the election in Sorens 2005 data $(1=$ regional; $0=$ national election). We expect voters to support regional parties more strongly in regional elections.

- Country FEs (fixed effects) are country dummies that capture specific (institutional, historical, cultural) characteristics of each country that might be correlated with support for regional parties.

Besides these variables (see table 1 for descriptive statistics; for the correlation between the main predictors, see table 8, appendix 6.2), additional controls are used for robustness checks. We control for the level of regional autonomy (regional_auton), irredentist potential (irredentist_potential), whether the region is part of a EU member state $(E U)$, it has past historical records of independence (hist_together; indep) and is the capital of the country (Capital), religious differences (religion), squared physical distance (distance_sq), the degree of multipartism (ENERP), and if some of its regional parties also contest elections in other regions (party_elsewhere) - for a description of these variables, see appendix 6.1 .

Although all these variables have been tested, some are excluded from the reported models for various reasons, such as having important endogeneity problems (e.g. 
the degree of autonomy already obtained by the region and $E N E R P$ ) or not being significant in several of the specifications. The latter includes some variables described above, such as distance_sq, EU, religion, indep, and capital, as well as other minor controls such as the legal status of the language (whether or not it is official), whether or not the region is in the mainland, population density and ideological gap, measured as the absolute difference in votes for left-wing parties in the territorial subunits for their respective last regional and general elections.

\subsection{The empirical model}

The estimation methodology used is a pooled ordinary lest squares (OLS) regression with country fixed effects and errors clustered at the regional level. ${ }^{18}$ This equation gives the main model specification:

$$
\begin{aligned}
& \text { Votes }_{j k t}=\alpha_{k}+\beta G D P \text { ratio }_{j t}+\text { distance }_{j}+\text { olanguage }_{j}+ \\
& \lambda\left(\text { distance } \times G D P \_ \text {ratio }\right)_{j t}+\gamma\left(G D P \_ \text {ratio } \times{\text { language })_{j t}}+\sum_{j=1}^{H} \theta_{h} X_{j t}+\epsilon_{j t} .\right.
\end{aligned}
$$

The percentage of votes for regionalist parties in region $j$, country $k$ and period $t$, is modelled as a function of GDP_ratio, distance, language, the interactions distance_GDP, language_GDP, and other controls $X$. As some model specifications include country dummies, there is a potential dependence of constant $\alpha$ $k$ on the country $k$, i.e.,

$$
\alpha_{k}=\alpha+\sum_{k=1}^{K-1} \omega_{k} 1_{1 \in k}
$$

where $1_{1 \in k}=1$ if region $i$ belongs to country $k$ and 0 otherwise.

Although $v \_r e g$ is the main dependent variable, electoral support for the two subtypes of regionalist parties, autonomists ( $\left.v \_a u t o n\right)$ and secessionists $\left(v \_s e c\right)$ are also used as dependent variables in some model specifications.

The main hypotheses from the theoretical framework are tested empirically in the following manner:

- Hypothesis 1: we expect that (at least one of) the coefficients for distance_GDP and language_GDP will be positive and significant. Formally:

$$
H_{o}=\lambda>0, \gamma>0
$$

\footnotetext{
${ }^{18}$ The earliest election in our data set is in 1969, the last in 2014. Data in this full interval of time are not available for all regions and elections. Even though historical and institutional differences between the countries might be important, given that the effect of country-level factors on the support for regionalism is not the focus of our study, we include country fixed effects.
} 
- Hypothesis 2a: a Wald test comparing the coefficients of the models for $v \_s e c$ using the full and separated samples should report statistical differences. The same holds for $v \_$auton.

- Hypothesis 2b: In the models for $v \_a u t o n$ and $v \_s e c$ using separated samples, the main coefficients should not be statistically different.

- Hypothesis 3: hypothesis 1 should hold also when explaining support for autonomist and secessionist parties separately. As we argue using the full sample would yield biased coefficients, we use the separated samples. At least either $\lambda$ or $\gamma$ should be significant in the corresponding regressions.

\subsection{Results}

Table 2, with the pooled OLS analysis of the determinants of $v \_r e g$ (large sample, errors clustered by region) gives the main results of the paper. The richest specification, including country fixed effects, is our preferred model (Column 4). Overall, the solid empirical evidence provided - supported by numerous robustness checks - confirms our four hypotheses. We analyze our results for each hypothesis next.

\section{Hypothesis 1}

The interaction terms distance_GDP and language_GDP have a positive effect on $v \_r e g$ at the $1 \%$ level (table 2). When the interactions are introduced into the model, the GDP_ratio is no longer significant. This means that relative regional per capita income accounts for regional party support through its interaction with cultural variables, and not by itself. Without the interaction terms, this coefficient is significant (columns 1 and 3, table 2) because of omitted variables bias. This interaction, which has been overlooked to date in empirical studies, is crucial for interpreting the main factors behind the support for regionalist parties.

To illustrate this, we analyze the marginal effects of this interaction in our preferred model (column 4, table 2). If a region is $100 \mathrm{~km}$ farther away from the capital of the country than another region, ceterisparibus, the expected difference in the percentage of votes cast for regionalist parties depends on GDP_ratio as given by:

$$
\frac{d v \_ \text {reg }}{\text { distance }}=1.53+2.18 G D P \_ \text {ratio. }
$$

Similarly, conditional upon the value of $G D P$ ratio, the effect of a marginal change in the proportion of speakers of a regional distinctive language on $v \_r e g$ is given by:

$$
\frac{d v \_ \text {reg }}{\text { dlanguage }}=20.44+43.66 G D P \_ \text {ratio. }
$$

Table 3 top shows the marginal effects of distance for different values of GDP_ratio. From the first row, we can see that a region located $600 \mathrm{~km}$ away from the capital 


\begin{tabular}{|c|c|c|c|c|}
\hline & $\begin{array}{c}(1) \\
\mathrm{v} \_r e g\end{array}$ & $\begin{array}{c}(2) \\
\mathrm{v} \_ \text {reg }\end{array}$ & $\begin{array}{c}(3) \\
\text { v_reg }\end{array}$ & $\begin{array}{c}(4) \\
\mathrm{v} \_ \text {reg }\end{array}$ \\
\hline GDP_ratio & $\begin{array}{c}19.82^{* * *} \\
(6.044)\end{array}$ & $\begin{array}{c}0.291 \\
(5.181)\end{array}$ & $\begin{array}{c}13.90^{* * *} \\
(4.093)\end{array}$ & $\begin{array}{l}-3.288 \\
(4.630)\end{array}$ \\
\hline distance & $\begin{array}{c}0.767^{* * *} \\
(0.252)\end{array}$ & $\begin{array}{c}1.695^{* * *} \\
(0.320)\end{array}$ & $\begin{array}{c}0.683^{* * *} \\
(0.215)\end{array}$ & $\begin{array}{c}1.528^{* * *} \\
(0.305)\end{array}$ \\
\hline language & $\begin{array}{c}23.09^{* * *} \\
(7.464)\end{array}$ & $\begin{array}{c}28.16^{* * *} \\
(5.950)\end{array}$ & $\begin{array}{c}17.03^{* * *} \\
(6.181)\end{array}$ & $\begin{array}{c}20.44^{* * *} \\
(5.915)\end{array}$ \\
\hline distance_GDP & & $\begin{array}{c}2.636^{* * *} \\
(0.736)\end{array}$ & & $\begin{array}{c}2.184^{* * *} \\
(0.676)\end{array}$ \\
\hline language_GDP & & $\begin{array}{c}52.71^{* * *} \\
(17.46)\end{array}$ & & $\begin{array}{c}43.66^{* * *} \\
(15.51)\end{array}$ \\
\hline year & & & $\begin{array}{l}0.152^{\text {*** }} \\
(0.0412)\end{array}$ & $\begin{array}{l}0.158^{* * *} \\
(0.0387)\end{array}$ \\
\hline has_neighbor & & & $\begin{array}{l}-2.763 \\
(2.932)\end{array}$ & $\begin{array}{c}-4.894^{*} \\
(2.691)\end{array}$ \\
\hline richer_neighbor & & & $\begin{array}{c}12.63^{* * *} \\
(3.339)\end{array}$ & $\begin{array}{c}11.54^{* * *} \\
(3.235)\end{array}$ \\
\hline population & & & $\begin{array}{c}-0.162^{* * *} \\
(0.0582)\end{array}$ & $\begin{array}{c}-0.165^{* * *} \\
(0.0511)\end{array}$ \\
\hline chamber_size & & & $\begin{array}{c}0.0849^{*} \\
(0.0493)\end{array}$ & $\begin{array}{c}0.113^{* * *} \\
(0.0419)\end{array}$ \\
\hline regional_elect & & & $\begin{array}{c}2.681^{* * *} \\
(0.677)\end{array}$ & $\begin{array}{c}2.453^{* * *} \\
(0.697)\end{array}$ \\
\hline Country FEs & No & No & Yes & Yes \\
\hline Observations & 1232 & 1232 & 1102 & 1102 \\
\hline$R^{2}$ & 0.317 & 0.420 & 0.531 & 0.587 \\
\hline Adjusted $R^{2}$ & 0.316 & 0.417 & 0.523 & 0.579 \\
\hline
\end{tabular}

Table 2 - Pooled ordinary least squares (OLS) model explaining votes for regionalist (autonomist + seccesionist) parties using the full sample. The constant term is excluded from the table for paucity reasons. Errors clustered at the regional level. Standard errors are given in parentheses. ${ }^{*} p<0.10,{ }^{* *}<0.05,{ }^{* *} p<0.01$. 
is, ceterisparibus, more likely to show a greater support for regional parties than one which is $500 \mathrm{~km}$ away. However, this effect is conditional on the relative economic affluence of the region. If the two hypothetical regions we are comparing are relatively poor, with the GDP per capita in the region being only half of that of the country $\left(G D P \_\right.$ratio $\left.=-0.5\right)$, being $100 \mathrm{~km}$ farther away implies an increase of $0.44 \%$ in votes casted for regionalist parties. If these two regions were very rich, with the GDP per capita of both regions being $80 \%$ larger than the national GDP per capita $\left(G D P \_\right.$ratio=0.8), being 100 kilometers farther away would imply a $3.28 \%$ increase in regionalist support. Similarly, if a region's per capita GDP equals the national average $\left(G D P \_\right.$ratio $\left.=0\right)$, there will be a $20.44 \%$ increase in votes for regionalist parties if everybody speaks a vernacular language relative to not having a regional language. If these two same regions are very rich in relative terms $\left(G D P \_\right.$ratio $\left.=0.8\right)$, regionalist electoral support will increase by $55.37 \%$. However, if these regions are very poor $\left(G D P \_\right.$ratio $\left.=-0.5\right)$, the marginal effect of language on $v \_r e g$ becomes negative. Hence, the model predicts that very poor and culturally differentiated regions will tend to be more centralist than equally poor regions which are more culturally similar to the rest of the country. ${ }^{19}$

The implications of the interaction term for the marginal effect of differences in GDP per capita between the region and the country are - even more-critical. Since the coefficient for GDP_ratio is not significant for any of our models with interactions, the marginal effect of a one-unit change in GDP_ratio on $v \_r e g$, is fully dependent on the value taken by the cultural variables, being 0 for a region whose culture is identified as the main culture in the country. ${ }^{20}$ Formally:

$$
\frac{d v \_ \text {reg }}{d G D P \_ \text {ratio }}=2.18 \text { distance }+43.66 \text { language } .
$$

3-bottom shows how the effect of GDP_ratio on regionalist vote depends on the distance at which the given region is from the capital of the country, and the proportion of speakers of a regional distinctive language. In two regions with no vernacular language, which are $100 \mathrm{~km}$ away from the capital and whose GDP_ratio differs by one unit, the predicted difference of regionalist support is only $2.18 \%$. This difference becomes much higher $(43.68 \%)$ for a $2000 \mathrm{~km}$ distance. The effect of the interaction with language is also very large: for two regions that have $25 \%$ of speakers of a vernacular language, the difference in expected support for regionalist parties would be $13.09 \%$ (if located at $100 \mathrm{~km}$ from the capital) and $54.59 \%$ (at $2000 \mathrm{~km}$ from the capital). With a $100 \%$ of vernacular language speakers in these regions, differences would become $45.84 \%$ and $87.34 \%$, respectively. ${ }^{21}$

To sum up, from these analyses, we conclude that the following:

\footnotetext{
${ }^{19}$ Beyond the scope of this paper, this finding presents an interesting avenue for inquiry for the social psychological literature on national identity (e.g. Bloom, 1993; Spinner-Halev and TheissMorse, 2003).

${ }^{20}$ We explored the implications of the region having the capital of the country in an unreported regression with a dummy. Its coefficient is not statistically significant once geographical distance is controlled for, and does not alter the results.

${ }^{21}$ This is an extreme case, but in fact more than $90 \%$ of the population speaks a vernacular language in some sub-units, such as the German-Speaking Communities in Belgium or the Faroe Islands in Denmark.
} 


\begin{tabular}{|c|cccc|}
\hline GDP_ratio & -0.5 & 0 & 0.5 & 0.8 \\
\hline $\begin{array}{c}\text { D v_reg } \\
\text { d distance }\end{array}$ & 0.44 & 1.53 & 2.62 & 3.28 \\
$\frac{\partial \text { v_reg }}{\text { d language }}$ & -1.39 & 20.44 & 42.27 & 55.37 \\
\hline
\end{tabular}

\begin{tabular}{|c|cccc|}
\hline & \multicolumn{5}{|c|}{ language } \\
$\frac{\partial v_{\text {reg }}}{\partial \text { GD_ratio }}$ & 0 & 0.25 & 0.5 & 1 \\
\hline 0 & 0 & 10.91 & 21.83 & 43.66 \\
100 & 2.18 & 13.09 & 24.01 & 45.84 \\
$\mathrm{~km} 500$ & 10.92 & 21.83 & 32.75 & 54.58 \\
1000 & 21.84 & 32.75 & 43.67 & 65.50 \\
2000 & 43.68 & 54.59 & 65.51 & 87.34 \\
& & & & \\
\hline
\end{tabular}

Table 3 - Top: Marginal effect of increasing distance by $100 \mathrm{~km}$ and language from 0 to 1 on support for regionalist parties for different values of GDP_ratio. Bottom: Marginal effect of GDP_ratio on support for regionalist parties for different values of distance and language.

1. The degree to which cultural differences between a region and the majoritarian culture in its country affect the support for regionalism in Western Europe is significantly influenced by relative regional affluence. Being more culturally differentiated is associated with a large gain in support for regionalism in relatively rich regions, but with a much smaller one for relatively poor ones.

2. Being relatively richer only increases support for regionalism in regions whose culture is significantly different from the predominant one in the country. 

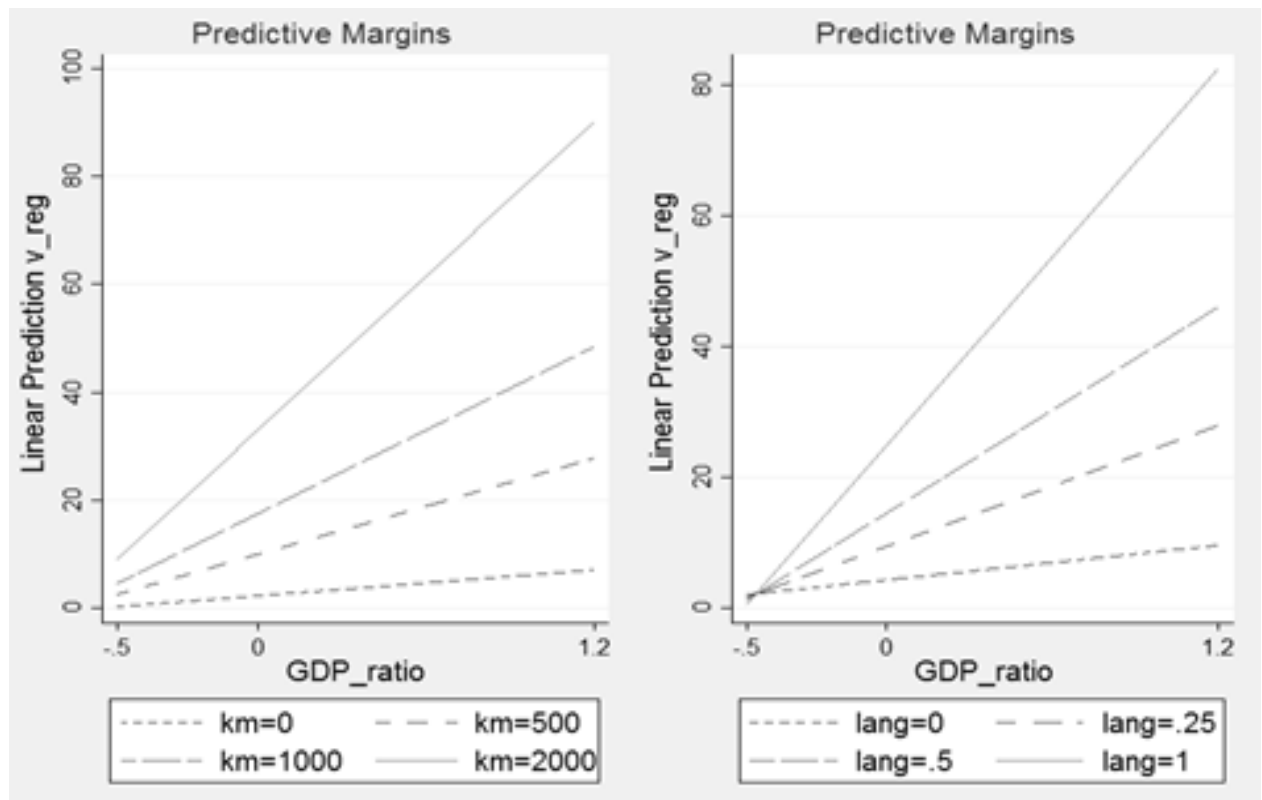

Figure 1 - LHS: Predicted vote for regional parties $\left(v \_r e g\right)$ as a function of $G D P \_$ratio for given values of distance (in $100 \mathrm{~km}$ ). RHS: Predicted vote for regional parties ( $v \_r e g$ ) as a function of GDP_ratio for given values of language (in proportion 0-1). The other variables are evaluated at their average values.

Figure 1 illustrates the relevance of the interaction term for the model predictions. An increase in GDP_ratio translates into different predictions of votes for regionalist parties depending on the distance at which the corresponding region is from the capital of the country. While regionalist parties in a relatively rich region with a GDP_ratio of 0.8 and located $500 \mathrm{~km}$ away from the capital of the country are expected to obtain around $20 \%$ of the votes, this share is almost $60 \%$ in a region located at $2000 \mathrm{~km}$ from the capital, keeping the other variables at their means. Equivalently, the effect of differences in distance on the share of votes for regionalist parties is much smaller for poor regions. When we compare two equivalent regions with a GDP_ratio of -0.5 but at 500 and $2000 \mathrm{~km}$ from the capital, we see that the difference in the percentage of predicted votes is less than $10 \%$. For the same difference in distance, the predicted share of votes for regionalist parties in two rich regions with a GDP_ratio of 0.8 differs by almost $40 \%$.

Similarly, for a relatively rich region $\left(G D P \_\right.$ratio=0.8), voting intention for regionalist parties fluctuates between $15 \%, 25 \%$ and $47 \%$, as the percentage of speakers of the regional distinctive language changes from $25 \%$, to $50 \%$ and $100 \%$, ceterisparibus. In a relatively poor region $\left(G D P \_\right.$ratio $\left.=-0.5\right)$, the predicted support for regionalists is almost 0 . In this case, having different proportions of speakers of a minority language does not affect regionalist voting.

We conducted several tests to check whether our findings are robust to different methodologies and specifications. Including only one of the two cultural variables and its interaction with $G D P \_$ratio is enough to cancel out the latter's effect and obtain a positive and significant interaction (table 9, appendix 6.2). Results hold if we use only the last regional election for every case $(\mathrm{N}=120$; table 10 , appendix 6.2 ), and if we run tobit models (table 12, appendix 6.2) which are left- and right- 
censored at 0 and 100 respectively to reflect the fact that the dependent variable, by definition, can never fall outside these bounds. The interaction between cultural and economic factors is also robust to instrument distance and distance_GDP with language and language_GDP in a 2SLS regression. ${ }^{22}$ This model should capture the exogenous effect of cultural distance and its interaction with GDP_ratio (table 11, appendix 6.2). Finally, the interactions are also robust to running a model with frequency weights, in which each region gets a weight proportional to its population (table 13, appendix 6.2).

Returning to the main model (regression 4, table 2), our controls report some significant effects. A 1 million increase in a region's population is associated with a decrease of a $1.65 \%$ in the expected percentage of votes for regionalist parties. This result is very robust across different specifications, ${ }^{23}$ and also for the models with either $v \_s e c$ or $v$ _auton as dependent variables - with the separated sample. ${ }^{24}$ Thus, having a larger weight on nationwide politics seems to ease regionalist aspirations. Coefficients associated to the variables year, regional_elect, chamber_size, and richer_neighbor are positive, as expected, while having a neighboring country which is poorer than the current one (has_neighbor $=1$ and richer_neighbor $=0$ ) decreases regionalist support - at the $10 \%$ level of significance. Including country fixed effects improves the explanatory capacity of the model, and does not have much impact on the size of coefficients.

\section{Hypotheses 2}

We proceed next to analyze whether $v \_s e c$ and $v \_r e g$ should be kept aggregated in $v \_r e g$ or should be better analyzed independently. We run a Wald test to test whether each coefficient is equal across the two models being compared. Table 4 reports the number of statistically different coefficients in each model comparison. ${ }^{25}$

The third row shows that the Wald test rejects the hypothesis of equal coefficients for three variables: there are three coefficients which are different between the model explaining $v$ _auton using the full sample, i.e. including those regions with some $v \_s e c$, and the model explaining $v$ _auton using the separated sample, only with regions without secessionist votes. When $v \_s e c$ becomes the dependent variable two statistically different coefficients are reported for the same models with different

\footnotetext{
${ }^{22}$ In this specification, the coefficient for distance_GDP is larger than in the main model. The effect of GDP_ratio on $v \_r e g$ becoming negative and significant for the 2SLS regression means that the population in not-culturally differentiated regions which are richer would vote less for regionalist parties than the population in poorer ones, taking the main thesis of the paper to the extreme.

${ }^{23}$ The negative significant coefficient for population holds also in non-reported robustness checks, such as including the contry's population, or the relative population of the region over the population of the country as regressors, or taking the log of the variable instead of the level.

${ }^{24}$ Population loses its significance and changes its sign only in the regressions with the full sample and $v \_s e c$ as the dependent variable (table 15, appendix 6.2). Note we contend throughout that these models are biased.

${ }^{25}$ The explanatory variables included in each of these models are the same as those included in the main model (Column 4, table 2). The models in the table are respectively: $v \_$sec sep (Column 2, 5); v_auton sep (Column 4, table 5); v_sec full (Column 2, table 15, appendix 6.2); and $v \_$auton full (Column 4, table 15, appendix 6.2).
} 


\begin{tabular}{|l|l|l|}
\hline Models compared & \# Diff. & Different coefficients \\
\hline \hline v_auton sep - v_sec sep & 0 & - \\
v_sec full - v_auton full & 0 & - \\
v_auton full - v_auton sep & 3 & year, language_GDP, language. \\
v_sec full - v_sec sep & 2 & richer_neighbor, population. \\
\hline
\end{tabular}

Table 4 - The number of different coefficients between the models. Wald test, 10\% level of significance. Full stands for the full sample, sep for the separated sample, which excludes the regions with a positive amount of the other type of regionalist vote.

samples (row 4). Hence, hypothesis 2a holds: for the models using $v \_s e c$ and $v \_$_auton as the dependent variables, the regression coefficients corresponding to the same variables across two different samples show statistically significant different results.

While the evidence provided so far is coherent with the argumentation for the coefficients in one of the models to be biased, it does not indicate which of the two options - full or separated sample - is better. Two pieces of evidence offer some guidance in this choice. The first - arguably limited - argument concerns explanatory capacity. The two models with the separated samples have a higher explanatory capacity than with the full samples $\left(R^{2}\right.$ is 0.52 vs 0.35 for $v \_s e c$ - columns 2 , table 5 and table 15, appendix 6.2 - and 0.62 vs 0.45 for $v$ _auton-columns 4 , table 5 and table 15 , appendix $6.2-$ ).

The second piece of evidence is given by the result of testing hypothesis $2 \mathrm{~b}$. It has been argued that if both $v \_s e c$ and $v \_$auton are explained by similar factors, the coefficients of a model studying these two phenomena together using a joint sample, would be biased. Hypothesis $2 \mathrm{~b}$ helps us in answering this question as it gives as a quantifiable measure of how different are the coefficients between the models explaining $v \_s e c$ and $v \_$auton. A Wald test does not reject the null hypothesis of the coefficients being equal for any of the variables - not even at the $10 \%$ level. This holds both for the models using the separated and full samples (rows 1 and 2, table 4). Hence, hypothesis $2 \mathrm{~b}$ is also satisfied, as there are no statistically different results between the coefficients in the models explaining the support for autonomist and secessionist parties.

In short, all available evidence supports aggregating the two sub-types of regionalist voting together. However, given that they have been frequently studied separately in the existing literature, it seems relevant to assess whether the main results for the determinants of $v \_r e g$, and specifically the interaction between cultural and economic factors, hold for each form of regionalism. 


\subsubsection{Hypothesis 3}

Since this paper points towards an important bias in the results for $v \_s e c$ and $v$ _auton using the full sample, we will test whether the interactions between cultural and economic variables are significant with separated samples. In order to shed light on the determinants of $v \_s e c$, we drop the observations with a positive value for $v$ _auton $(\mathrm{N}=759)$, and conversely we drop the positive observations for $v$ _auton when studying $v \_s e c(\mathrm{~N}=822)(5)$.

Although distance_GDP loses its significance, ${ }^{26}$ the interaction language_GDP keeps it, thus confirming hypothesis 3. Also, the effect of GDP_ratio vanishes as we bring in the interactions. These findings are robust to using Tobit instead of OLS, including frequency weights, using only the last cross-section of the data, running a 2SLS model (instrumenting distance and its interaction with language and its interaction), and including only one of the cultural variables and its interaction. Some minor exceptions aside, ${ }^{27}$ hypothesis 3 is satisfied and the interaction effect between cultural and economic variables is positive and significant in models explaining secessionism and autonomism.

Despite potential concerns regarding research design (i.e. the samples have been artificially separated), as the results for secessionist and autonomist support are consistent and comparable to those for $v \_r e g$, the interdependency of cultural and economic explanatory factors is reinforced.

\subsubsection{Exploring other variables and related robustness checks}

This section briefly explores the additional controls used, on top of those reported in the tables. Some of these controls are excluded because they were not significant in the main regression, or not robust to different specifications, and do not modify any result significantly. ${ }^{28}$ The other reason to exclude some of the controls was their endogeneity problem, namely regional_auton and ENERP. These two variables have played a preeminent role in the literature so far (e.g. Sorens, 2005; Massetti, 2009), but suffer from an important problem of simultaneity, as they are directly affected by the dependent variable. To tackle this problem, we have instrumented them with more exogenous variables.

ENERP is instrumented through chamber_size, a crucial aspect in the magnitude of district (Taagepera and Shugart, 1989), and a 2SLS regression is run. We find a 2SLS positive and significant coefficient for ENERP $-F$-statistic test for weak instruments $=9.10(p=0.0031)$ - implying that a higher degree of multipartism is

\footnotetext{
${ }^{26}$ The $p$-value for distance_GDP is 0.105 though —Column 4, table 5 .

${ }^{27}$ There are two exceptions. With $v \_s e c$ as the dependent variable, if only distance and its interaction are included as cultural variables, neither $G D P$ _ratio nor the GDP_distance interaction are significant, and if we use only the last cross section, the interactions are not significant $(\mathrm{N}=75)$.

${ }^{28}$ These include distance_sq, EU, religion, indep, and capital, as well as the legal status of the language (whether or not if it is official), whether or not the region is in the mainland, population density, the population of the country, the proportional population of the region over that of the country, and the ideological gap.
} 


\begin{tabular}{|c|c|c|c|c|}
\hline & $\begin{array}{c}(1) \\
\mathrm{v} \_\mathrm{sec}\end{array}$ & $\begin{array}{c}(2) \\
\mathrm{v} \_ \text {sec }\end{array}$ & $\begin{array}{c}(3) \\
\mathrm{v} \_ \text {auton }\end{array}$ & $\begin{array}{c}(4) \\
\mathrm{v}_{\text {__auton }}\end{array}$ \\
\hline GDP_ratio & $\begin{array}{l}5.584^{*} \\
(3.023)\end{array}$ & $\begin{array}{l}-0.720 \\
(5.099)\end{array}$ & $\begin{array}{l}9.046^{* *} \\
(4.267)\end{array}$ & $\begin{array}{l}-6.875^{*} \\
(3.601)\end{array}$ \\
\hline distance & $\begin{array}{c}0.619 \\
(0.471)\end{array}$ & $\begin{array}{c}0.638 \\
(0.481)\end{array}$ & $\begin{array}{c}0.438^{* * *} \\
(0.162)\end{array}$ & $\begin{array}{c}1.025^{* * *} \\
(0.294)\end{array}$ \\
\hline language & $\begin{array}{c}5.266^{*} \\
(3.024)\end{array}$ & $\begin{array}{l}12.89^{* *} \\
(5.018)\end{array}$ & $\begin{array}{c}5.905 \\
(4.133)\end{array}$ & $\begin{array}{c}16.01^{* * *} \\
(4.469)\end{array}$ \\
\hline distance_GDP & & $\begin{array}{c}0.135 \\
(1.434)\end{array}$ & & $\begin{array}{c}1.128 \\
(0.690)\end{array}$ \\
\hline language_GDP & & $\begin{array}{c}40.33^{* * *} \\
(13.83)\end{array}$ & & $\begin{array}{c}63.66^{* * *} \\
(13.76)\end{array}$ \\
\hline year & $\begin{array}{l}0.102^{* * *} \\
(0.0287)\end{array}$ & $\begin{array}{l}0.103^{* * *} \\
(0.0277)\end{array}$ & $\begin{array}{c}0.0957^{* * *} \\
(0.0316)\end{array}$ & $\begin{array}{l}0.111^{* * *} \\
(0.0320)\end{array}$ \\
\hline has_neighbor & $\begin{array}{c}0.664 \\
(1.338)\end{array}$ & $\begin{array}{l}-1.060 \\
(1.396)\end{array}$ & $\begin{array}{c}1.102 \\
(1.368)\end{array}$ & $\begin{array}{l}-2.003 \\
(1.235)\end{array}$ \\
\hline richer_neighbor & $\begin{array}{l}5.842^{* *} \\
(2.685)\end{array}$ & $\begin{array}{l}5.653^{* *} \\
(2.663)\end{array}$ & $\begin{array}{l}5.791^{* *} \\
(2.430)\end{array}$ & $\begin{array}{c}5.104^{* * *} \\
(1.839)\end{array}$ \\
\hline population & $\begin{array}{l}-0.115^{* *} \\
(0.0497)\end{array}$ & $\begin{array}{l}-0.118^{* *} \\
(0.0468)\end{array}$ & $\begin{array}{l}-0.157^{* *} \\
(0.0610)\end{array}$ & $\begin{array}{c}-0.130^{* * *} \\
(0.0433)\end{array}$ \\
\hline chamber_size & $\begin{array}{l}0.0804^{* *} \\
(0.0404)\end{array}$ & $\begin{array}{l}0.0906^{* *} \\
(0.0378)\end{array}$ & $\begin{array}{c}0.0778^{*} \\
(0.0395)\end{array}$ & $\begin{array}{c}0.0900^{* * *} \\
(0.0343)\end{array}$ \\
\hline regional_elect & $\begin{array}{c}1.279 \\
(0.793)\end{array}$ & $\begin{array}{c}1.254 \\
(0.777)\end{array}$ & $\begin{array}{c}1.226^{* * *} \\
(0.384)\end{array}$ & $\begin{array}{c}1.084^{* * *} \\
(0.366)\end{array}$ \\
\hline Country FEs & Yes & Yes & Yes & Yes \\
\hline Observations & 759 & 759 & 822 & 822 \\
\hline$R^{2}$ & 0.492 & 0.519 & 0.459 & 0.619 \\
\hline Adjusted $R^{2}$ & 0.480 & 0.506 & 0.447 & 0.609 \\
\hline
\end{tabular}

Table 5 - Vote for secessionist and autonomist parties. Pooled ordinary least squares $(O L S)$ model explaining votes for secessionist (columns 1 and 2) and autonomist parties (columns 3 and 4). The regression for each type of regionalist vote excludes those regions with a positive amount of the other type of regionalist vote (separate samples). Errors are clustered at the regional level. The constant term is excluded for paucity. Standard errors are given in parentheses. ${ }^{*} p<0.10,{ }^{* *}<0.05,{ }^{* * *} p<0.01$. 
associated with a better electoral performance of regionalist parties (Column 1, table 14, appendix 6.2). Similarly, we instrument regional_auton with hist_together. While the $F$-statistic of excluded instruments for the first stage is a bit low (2.65, $p=0.106$ ), the 2SLS coefficient for region_auton is 29.17 , and significant at the $1 \%$ (see column 2, table 14, appendix 6.2). This points towards higher regional autonomy having a positive effect on regionalist support.

There are two additional caveats to our results: (1) the main model does not take into account irredentist particularities, and (2) some parties are present in several regions at the same time, which might make these observations non-independent.

When we incorporate irredentist_potential into our model, it does not have an impact on regionalist voting and does not change our findings (Column 4, 2). Additionally, when we drop the 18 territorial units where this variable was positive, our main results still hold (see column 3, table 14, appendix 6.2). To control for potential problems derived from the same regionalist parties contesting elections in different regions, we include the party_elsewhere variable. Again, when we include this variable in the regression it is not significant and does not affect the results. These are also robust to dropping the observations corresponding to the 17 regions with relevant regional parties contending in some other region (e.g. Lega Nord, PNV, etc.) (see column 4, table 14, appendix 6.2).

\section{Conclusions}

This paper analyzes the effect of cultural and economic factors on voters' desire for greater regional autonomy and independence using a panel of territorial subunits in 10 West European democracies. We extended the traditional theory using the concept of cultural proximity. The main argument is that the population of richer regions is more likely to tolerate transfers to poorer regions as long as they feel part of the same national group. In relatively rich and culturally differentiated regions, there should be a larger political support for regionalism. This hypothesis is tested empirically using a data set with the results from regional elections in these countries between 1969 and 2000 - updated with the most recent elections till 2014. Evidence in support of the predictions of the theoretical framework is found in the form of statistically significant interaction effects between cultural and economic variables.

Moreover, regional relative affluence only has a positive effect on the support for regionalism through these interaction terms: a region being relatively richer is only associated with an expected higher support for regionalist parties to the extent that it is culturally differentiated (i.e., the proportion of minority language speakers and physical distance are larger). Equivalently, the degree to which a region's cultural difference is associated with a higher support for regionalist parties depends on its relative income, as this effect is much larger for rich than for poor regions. Also, both theory and empirical evidence suggest that support for autonomist and secessionist parties should be considered together in electoral studies: the interaction between income and culture underpins both, and there are good reasons to think that models using common samples to study these two phenomena separately will be biased. 
Further research is necessary to unravel plausible interaction effects between income and cultural variables beyond Western Europe, and also to understand why the interactions do not hold for some particular cases. Additional theoretical and empirical studies that incorporate microdata should complement this study by analyzing whether this interaction effect applies at an individual voter level - and, in that case, exploring the concrete mechanism that might explain it. Also, locating all (regionalist and nonregionalist parties) that compete in an election on a territorial continuum that ranges from extreme secessionism to maximum unionism (e.g., on the basis of party manifestos per each election) might help us to understand further how this interaction operates.

To summarize, the main theses of the paper are supported by our empirical analyses. Firstly, cultural and economic factors affect regionalist voting through a positive and significant interaction - this even makes the relative affluence of the region insignificant on its own. Secondly, keeping aggregated autonomist and secessionist electoral support in a unique regionalist category — instead of considering them as two separated phenomena - seems more adequate. Finally, the significant interaction between income and culture in the separate explanation of autonomist and secessionist support reinforces its relevance in any electoral study of minority nationalism. 


\section{Appendix}

\subsection{Description of main unreported controls}

- Regional_auton: The level of autonomy already obtained by the region at the time of the corresponding election, taking values 0 (less autonomous) to 4 most autonomous. If included as a control, the coefficient associated to this variable is positive and highly significant. This variable, borrowed from Sorens 2005, suffers from a serious endogeneity problem produced by simultaneity, as regions with a higher electoral support for regionalist parties tend to obtain higher quotas of autonomy. We instrument this variable with hist_together.

- Hist_together is used as instrument for regional_auton. As regions relatively recently annexed to their current country will tend to show a higher support for regionalist parties, we create a dummy variable which takes the value 1 if the region has always been part of the country since 1648, and 0 otherwise. The year 1648, when the Treaty of Westphalia was signed, marks the "end of the feudal system of family properties and the beginning of modern state nationalism" (Sorens 2005: 309). Having been part of the union since then might be associated with lower support for regionalism.

- Indep is a dummy variable similar to Hist_together - but less restrictive - and borrowed from Sorens 2005. It takes value 1 if the region has declared itself an independent country or served as the capital province of an independent country different from the current state at any point since 1648.

- ENERP: Effective Number of Electoral Regional Parties. As regionalist parties are often small, highly disproportional systems that reduce party choices are supposedly detrimental to them. The formula by Laakso and Taagepera 1979 (Sorens, 2005) is adapted:

$$
E N E R P=\frac{1}{\sum_{i=1}^{n} p_{i}^{2}}
$$

where $n$ is the number of parties and $p_{i}^{2}$ is the square of each party's proportion of all votes. Note that if a higher ENERP is the consequence of larger support for regionalist parties, as one could expect, there is a problem of endogeneity. Hence, we instrument ENERP trough chamber_size in some robustness checks.

- Religion is a dummy coded as 1 if at least $10 \%$ of the regional population's creed differs from the majoritarian one in the country.

- Distance_sq is the squared distance, frequently included in gravity models. As the effect of distance is expected to decrease as distance becomes larger, this variable should have a negative coefficient.

- A dummy to control whether the capital of the country is in the region.

- A dummy to control whether the region is part of a $E U$ member state. 
- In order to control for spatial autocorrelation, a dummy variable party_elsewhere is created. It takes value 1 if there is a regionalist party in the region which is also present and gains relevant support in another region, and 0 otherwise.

- Following Sorens 2005, we take into account the specific subtype of separatism, irredentism, that might bias our findings. A dummy variable irredentist_potential equals 1 if a region has a neighboring country which main language is the same as the regional language, and 0 otherwise. 


\subsection{Tables}

\begin{tabular}{|l|l|}
\hline Country & Regions \\
\hline \hline France & $\begin{array}{l}\text { Alsace, Aquitaine, Auvergne, Brittany, Burgundy, Cen- } \\
\text { tre, Champagne-Ardenne, Corsica, Franche-Comte, Guade- } \\
\text { loupe, Guiana, Ile-de-France, La Reunion, Languedoc- } \\
\text { Roussillon, Limousin, Lorraine, Lower Normandy, Mar- } \\
\text { tinique, Midi-Pyrenees, Nord-Pas-de-Calais, Pays de la } \\
\text { Loire, Picardy, Poitou-Charentes, Provence-Alpes-Cote } \\
\text { d'Azur, Rhone-Alpes, Upper Normandy }\end{array}$ \\
\hline Germany & $\begin{array}{l}\text { Baden-Wurttemberg, Bavaria, Berlin, Brandenburg, Bre- } \\
\text { men, Hamburg, Hesse, Mecklenburg-Vor, Lower Saxony, } \\
\text { North Rhine-Westphalia, Rhineland-Palatinate, Saarland, } \\
\text { Saxony, Saxony-Anhalt, Schleswig-Holstein, Thuringia }\end{array}$ \\
\hline Italy & $\begin{array}{l}\text { Abruzzo, AostaValley, Apulia, Basilicata, Calabria, Campa- } \\
\text { nia, Emilia-Romagna, Friuli-VG, Lazio, Liguria, Lombardia, } \\
\text { Marche, Molise, Piedmont, Sardinia, Sicily, Tuscany, Um- } \\
\text { bria, Veneto, Trentino-South Tyrol }\end{array}$ \\
\hline Portugal & Azores, Madeira \\
\hline Spain & $\begin{array}{l}\text { Andalusia, Aragon, Asturias, Balearic Islands, Basque } \\
\text { Country, Canary Islands, Cantabria, Castile La Mancha, } \\
\text { Castile and Leon, Catalonia, Extremadura, Galicia, La Ri- } \\
\text { oja, Madrid, Murcia, Navarre, Valencia, Ceuta,Melilla }\end{array}$ \\
\hline $\begin{array}{l}\text { Scotland, Wales, Northern Ireland, Gibraltar } \\
\text { Burgenland, Carinthia, Lower Austria, Salzburg, Styria, Ty- } \\
\text { rol, Upper Austria, Vienna, Vorarlberg }\end{array}$ \\
\hline $\begin{array}{l}\text { Hovedstaden, Midtjylland, Nordjylland, Sjælland, Syddan- } \\
\text { Nark, Faroe Islands }\end{array}$ \\
\hline Dether- \\
Belgium & $\begin{array}{l}\text { Groningen, Friesland, Drenthe, Overijssel, Gelderland, } \\
\text { Flevoland, Utrecht, Noord-Holland, Zuid-Holland, Zeeland, } \\
\text { Noord-Brabant, Limburg }\end{array}$ \\
$\begin{array}{l}\text { Flanders, Wallonia, Brussels, German-speaking communi- } \\
\text { ties }\end{array}$ \\
\hline
\end{tabular}

Table 6 - List of Regions included in the analysis 


\begin{tabular}{|c|c|c|c|c|c|}
\hline Country & Region & $\begin{array}{l}\text { Secessionist } \\
\text { parties }\end{array}$ & V. sec (\%) & Autonomist parties & $\begin{array}{l}\text { V. aut } \\
(\%)\end{array}$ \\
\hline It & $\begin{array}{l}\text { Emilia-Romagna, } \\
\text { Friuli-VG, Liguria, } \\
\text { Lombardia, Marche, } \\
\text { Piedmont, Tuscany, } \\
\text { Umbria, Veneto }\end{array}$ & Lega Nord & $\begin{array}{lr}13.7, & 8.3, \\
10.2, & 13, \\
6.3, & 16.7 \\
6.5, & 4.3, \\
35.5 & \end{array}$ & & \\
\hline It & Sardinia & $\begin{array}{l}\text { PdS, iRS, Pro- } \\
\text { gReS }\end{array}$ & 6.2 & RM, PSd'Az, RS, UDS & 17.5 \\
\hline It & Sicily & & & PdS, GS, PC & 21.4 \\
\hline It & Trentino & LN & 6.2 & $\begin{array}{l}\text { UPT, PATT, PT, CT, } \\
\text { AT }\end{array}$ & 45.7 \\
\hline It & South Tyrol & $\mathrm{STF}, \mathrm{F}, \mathrm{BU}$ & 27.2 & SVP, VGV, TA, AAC & 59 \\
\hline It & Molise & & & GS & 5.1 \\
\hline UK & Gibraltar & & & GSD, LP, GSLP & 100 \\
\hline UK & Scotland & SNP, SGP & 48.4 & & \\
\hline UK & Northern Ireland & $\mathrm{SF}$ & 30 & SDLP & 12.2 \\
\hline UK & Wales & $\mathrm{PC}$ & 17.9 & & \\
\hline $\mathrm{Be}$ & Flanders & N-VA, VB & 37.8 & & \\
\hline $\mathrm{Be}$ & Brussels & N-VA, VB & 2.7 & FDF & 13.1 \\
\hline $\mathrm{Be}$ & Germ-speak comm. & & & ProDG & 22.2 \\
\hline $\mathrm{Au}$ & Tyrol & $\begin{array}{l}\text { STF, LN-Alto } \\
\text { Adige, }\end{array}$ & 9.7 & SVP, CU-Lad & 47.8 \\
\hline $\mathrm{Au}$ & Burgerland & & & LBL & 4 \\
\hline Neth & Groningen & & & $\begin{array}{l}\text { Partij voor het Noor- } \\
\text { den }\end{array}$ & 3.15 \\
\hline Neth & Friesland & & & $\begin{array}{l}\text { FNP, P. voor het Noor- } \\
\text { den }\end{array}$ & 9.5 \\
\hline Neth & Utrecht & & & $\begin{array}{l}\text { PLP Utrecht, Mooi } \\
\text { Utrecht }\end{array}$ & 0.55 \\
\hline Neth & Noord-Holland & & & $\mathrm{ONH}$ & 1.88 \\
\hline Neth & Zeeland & & & Partij voor Zeeland & 5.66 \\
\hline Denm & Faroe Islands & $\mathrm{FF}, \mathrm{T}, \mathrm{F}$ & 47.1 & $\mathrm{SSF}, \mathrm{MF}$ & 10.4 \\
\hline Po & Azores & & & PDA & 0.49 \\
\hline Ger & Bavaria & $\mathrm{BP}$ & 2.1 & $\mathrm{DF}$ & 0.74 \\
\hline Ger & Schleswig-Holstein & & & SSW & 4.6 \\
\hline $\mathrm{Sp}$ & Andalusia & & & PA & 2.5 \\
\hline $\mathrm{Sp}$ & Aragon & & & PAR, CHA & 18 \\
\hline Sp & Asturias & & & FAC & 25.2 \\
\hline $\mathrm{Sp}$ & Balearic Islands & EQUERRA & 1.3 & $\begin{array}{l}\text { PSM, IB-LLIGA, CxI, } \\
\text { ENE, Ume }\end{array}$ & 12.7 \\
\hline $\mathrm{Sp}$ & Basque Country & $\begin{array}{lr}\text { PNV, } & \text { EHB/- } \\
\text { Bildu, } & \text { A, } \\
\text { EA } & \end{array}$ & 59.6 & & \\
\hline Sp & Canary Islands & & & CC, Nca & 35 \\
\hline Sp & Cantabria & & & PRC & 29.8 \\
\hline $\mathrm{Sp}$ & Castile and Leon & & & UPL & 1.9 \\
\hline $\mathrm{Sp}$ & Catalonia & $\begin{array}{l}\text { CDC, ERC, } \\
\text { CUP }\end{array}$ & 39.9 & UDC, ICV & 15.6 \\
\hline $\mathrm{Sp}$ & Galicia & $\mathrm{BNG}$ & 10.2 & ANOVA, CxG & 15 \\
\hline Sp & La Rioja & & & $\mathrm{PR}$ & 5.6 \\
\hline $\mathrm{Sp}$ & Navarre & $\begin{array}{lr}\text { PNV, } & \text { EHB/- } \\
\text { Bildu, } & \text { A, } \\
\text { NaBai } & \end{array}$ & 29.4 & UPN, CDN & 36.8 \\
\hline $\mathrm{Sp}$ & Valencia & & & $\mathrm{COM}$ & 7.4 \\
\hline Sp & Ceuta & & & CAB & 14.5 \\
\hline $\mathrm{Sp}$ & Melilla & & & $\mathrm{CM}, \mathrm{PPL}$ & 30.9 \\
\hline Fr & Alsace & & & Alsace d'Abord & 25.9 \\
\hline $\mathrm{Fr}$ & Aquitaine & $\mathrm{PNV}, \mathrm{AB}$ & 0.7 & & \\
\hline Fr & Brittany & $\mathrm{BP}$ & 4.3 & Terres de Bretagne & 2.6 \\
\hline $\mathrm{Fr}$ & Corsica & CL & 9.4 & $\mathrm{PNC}$ & 18.4 \\
\hline $\mathrm{Fr}$ & La Reunion & NR & 0.9 & PCR & 30.2 \\
\hline $\mathrm{Fr}$ & Martinique & $\begin{array}{l}\text { PPM, RDM, } \\
\text { BPM }\end{array}$ & 51 & MIM & 32.2 \\
\hline $\mathrm{Fr}$ & Pays de la Loire & $\mathrm{BP}$ & 1 & & \\
\hline $\mathrm{Fr}$ & $\begin{array}{l}\text { Provence-Alpes-Cote } \\
\text { d'Azur }\end{array}$ & & & LS & 2.7 \\
\hline
\end{tabular}

Table 7 - Classification of regionalist political parties and votes - in the last regional election considered till 2014 - in percentage. 


\begin{tabular}{|l|ccccccc|}
\hline & v_reg & v_sec & v_aut & GDP_rat. & dist. & lang. & dist_GDP \\
\hline v_reg & 1 & & & & & & \\
v_sec & 0.768 & 1 & & & & & \\
v_auton & 0.7757 & 0.1927 & 1 & & & & \\
GDP_ratio & 0.2445 & 0.1770 & 0.2005 & 1 & & & \\
distance & 0.3197 & 0.1592 & 0.3334 & -0.1155 & 1 & & \\
language & 0.4207 & 0.2909 & 0.3584 & -0.0575 & 0.2182 & 1 & \\
dist_GDP & -0.0300 & 0.0239 & -0.0697 & 0.3670 & -0.8078 & -0.1418 & 1 \\
lang_GDP & 0.1497 & 0.0791 & 0.1516 & 0.6602 & -0.2040 & -0.4007 & 0.4082 \\
\hline
\end{tabular}

Table 8 - Correlations between the main variables related to regionalist support, income and cultural differences. 


\begin{tabular}{|c|c|c|c|c|}
\hline & $\begin{array}{c}(1) \\
\text { v_reg }\end{array}$ & $\begin{array}{c}(2) \\
\mathrm{v} \_ \text {reg }\end{array}$ & $\begin{array}{c}(3) \\
\mathrm{v} \_ \text {reg }\end{array}$ & $\begin{array}{c}(4) \\
\text { v_reg }\end{array}$ \\
\hline GDP_ratio & $\begin{array}{c}10.05^{* * *} \\
(3.787)\end{array}$ & $\begin{array}{c}0.707 \\
(5.023)\end{array}$ & $\begin{array}{c}14.02^{* * *} \\
(4.255)\end{array}$ & $\begin{array}{c}2.332 \\
(4.582)\end{array}$ \\
\hline distance & $\begin{array}{c}0.898^{* * *} \\
(0.260)\end{array}$ & $\begin{array}{c}2.035^{* * *} \\
(0.463)\end{array}$ & & \\
\hline distance_GDP & & $\begin{array}{c}3.205^{* * *} \\
(0.955)\end{array}$ & & \\
\hline language & & & $\begin{array}{c}22.08^{* * *} \\
(7.079)\end{array}$ & $\begin{array}{c}28.78^{* * *} \\
(7.411)\end{array}$ \\
\hline language_GDP & & & & $\begin{array}{c}49.47^{* * *} \\
(16.03)\end{array}$ \\
\hline year & $\begin{array}{l}0.149^{* * *} \\
(0.0437)\end{array}$ & $\begin{array}{l}0.158^{* * *} \\
(0.0416)\end{array}$ & $\begin{array}{l}0.193^{* * *} \\
(0.0442)\end{array}$ & $\begin{array}{l}0.196^{* * *} \\
(0.0434)\end{array}$ \\
\hline has_neighbor & $\begin{array}{l}-2.838 \\
(3.220)\end{array}$ & $\begin{array}{l}-3.513 \\
(3.005)\end{array}$ & $\begin{array}{l}-2.808 \\
(3.152)\end{array}$ & $\begin{array}{l}-4.693 \\
(3.114)\end{array}$ \\
\hline richer_neighbor & $\begin{array}{c}14.06^{* * *} \\
(3.875)\end{array}$ & $\begin{array}{c}12.65^{* * *} \\
(3.642)\end{array}$ & $\begin{array}{c}12.49^{* * *} \\
(3.405)\end{array}$ & $\begin{array}{c}12.14^{* * *} \\
(3.347)\end{array}$ \\
\hline population & $\begin{array}{c}-0.217^{* * *} \\
(0.0629)\end{array}$ & $\begin{array}{c}-0.234^{* * *} \\
(0.0593)\end{array}$ & $\begin{array}{l}-0.141^{* *} \\
(0.0615)\end{array}$ & $\begin{array}{l}-0.122^{* *} \\
(0.0557)\end{array}$ \\
\hline chamber_size & $\begin{array}{c}0.133^{* *} \\
(0.0535)\end{array}$ & $\begin{array}{l}0.157^{* * *} \\
(0.0505)\end{array}$ & $\begin{array}{c}0.0605 \\
(0.0526)\end{array}$ & $\begin{array}{c}0.0649 \\
(0.0471)\end{array}$ \\
\hline regional_elect & $\begin{array}{c}2.773^{* * *} \\
(0.690)\end{array}$ & $\begin{array}{c}2.691^{* * *} \\
(0.691)\end{array}$ & $\begin{array}{c}2.883^{* * *} \\
(0.681)\end{array}$ & $\begin{array}{c}2.689^{* * *} \\
(0.698)\end{array}$ \\
\hline Country FEs & Yes & Yes & Yes & Yes \\
\hline Observations & 1102 & 1102 & 1102 & 1102 \\
\hline$R^{2}$ & 0.481 & 0.534 & 0.484 & 0.511 \\
\hline Adjusted $R^{2}$ & 0.473 & 0.526 & 0.476 & 0.502 \\
\hline
\end{tabular}

Table 9 - Vote for regionalist parties, using only one cultural variable and its interaction with GDP_ratio. Pooled OLS model explaining votes for regionalist (autonomist + secessionist) parties using the full sample. The constant term is excluded from the table for paucity. Errors clustered at the regional level. Standard errors in parentheses. $* p<0.10, * * p<0.05, * * * p<0.01$. 


\begin{tabular}{|c|c|c|c|c|}
\hline & $\begin{array}{c}(1) \\
\mathrm{v} \_ \text {reg }\end{array}$ & $\begin{array}{c}(2) \\
\mathrm{v} \_r e g\end{array}$ & $\begin{array}{c}(3) \\
\mathrm{v} \_ \text {reg }\end{array}$ & $\begin{array}{c}(4) \\
\text { v_reg }\end{array}$ \\
\hline GDP_ratio & $\begin{array}{c}30.15^{* * *} \\
(10.43)\end{array}$ & $\begin{array}{l}-3.179 \\
(7.356)\end{array}$ & $\begin{array}{c}22.41^{* * *} \\
(5.776)\end{array}$ & $\begin{array}{l}-4.782 \\
(7.534)\end{array}$ \\
\hline distance & $\begin{array}{l}0.353^{* *} \\
(0.172)\end{array}$ & $\begin{array}{c}1.094^{* * *} \\
(0.372)\end{array}$ & $\begin{array}{l}0.461^{* *} \\
(0.182)\end{array}$ & $\begin{array}{l}1.117^{* *} \\
(0.499)\end{array}$ \\
\hline language & $\begin{array}{c}31.00^{* * *} \\
(6.564)\end{array}$ & $\begin{array}{c}38.68^{* * *} \\
(7.562)\end{array}$ & $\begin{array}{c}20.33^{* * *} \\
(6.958)\end{array}$ & $\begin{array}{c}25.31^{* * *} \\
(8.568)\end{array}$ \\
\hline distance_GDP & & $\begin{array}{c}1.439 \\
(0.974)\end{array}$ & & $\begin{array}{l}1.210 \\
(1.127)\end{array}$ \\
\hline language_GDP & & $\begin{array}{c}103.1^{* * *} \\
(30.12)\end{array}$ & & $\begin{array}{c}76.68^{* * *} \\
(28.84)\end{array}$ \\
\hline year & & & $\begin{array}{l}-1.637 \\
(1.417)\end{array}$ & $\begin{array}{l}-0.916 \\
(1.389)\end{array}$ \\
\hline has_neighbor & & & $\begin{array}{c}0.469 \\
(2.900)\end{array}$ & $\begin{array}{l}-3.784 \\
(2.734)\end{array}$ \\
\hline richer_neighbor & & & $\begin{array}{c}12.89^{* * *} \\
(4.073)\end{array}$ & $\begin{array}{c}13.31^{* * *} \\
(3.866)\end{array}$ \\
\hline population & & & $\begin{array}{c}-0.166^{*} \\
(0.0856)\end{array}$ & $\begin{array}{c}-0.199^{* *} \\
(0.0903)\end{array}$ \\
\hline chamber_size & & & $\begin{array}{c}0.0435 \\
(0.0732)\end{array}$ & $\begin{array}{c}0.130 \\
(0.0803)\end{array}$ \\
\hline Country FEs & No & No & Yes & Yes \\
\hline Observations & 120 & 120 & 120 & 120 \\
\hline$R^{2}$ & 0.370 & 0.535 & 0.645 & 0.711 \\
\hline Adjusted $R^{2}$ & 0.354 & 0.514 & 0.586 & 0.656 \\
\hline
\end{tabular}

Table 10 - Vote for regionalist parties. Cross sectional OLS model explaining votes for regionalist (autonomist + secessionist) parties using the reduced sample, which only includes observations compiled by the authors. The constant term is excluded from the regression tables for paucity. Errors clustered at the regional level. Standard errors in parentheses. $* p<0.10, * * p<0.05, * * * p<0.01$. 


\begin{tabular}{|c|c|c|c|c|}
\hline & $\begin{array}{c}(1) \\
\mathrm{v} \_ \text {reg }\end{array}$ & $\begin{array}{c}(2) \\
\mathrm{v} \_ \text {reg }\end{array}$ & $\begin{array}{c}(3) \\
\text { v_reg }\end{array}$ & $\begin{array}{c}(4) \\
\mathrm{v} \_ \text {reg }\end{array}$ \\
\hline GDP_ratio & $\begin{array}{c}33.03^{* * *} \\
(8.567)\end{array}$ & $\begin{array}{l}-16.91 \\
(19.61)\end{array}$ & $\begin{array}{c}13.47^{* * *} \\
(4.179)\end{array}$ & $\begin{array}{c}-21.06^{* *} \\
(9.724)\end{array}$ \\
\hline distance & $\begin{array}{c}5.817^{* * *} \\
(1.911)\end{array}$ & $\begin{array}{c}9.812^{* * *} \\
(3.302)\end{array}$ & $\begin{array}{c}2.986^{* * *} \\
(0.943)\end{array}$ & $\begin{array}{c}5.559^{* * *} \\
(1.402)\end{array}$ \\
\hline distance_GDP & & $\begin{array}{c}16.53^{*} \\
(8.576)\end{array}$ & & $\begin{array}{c}11.08^{* * *} \\
(3.793)\end{array}$ \\
\hline year & & & $\begin{array}{c}0.0127 \\
(0.0701)\end{array}$ & $\begin{array}{c}0.135^{* *} \\
(0.0668)\end{array}$ \\
\hline has_neighbor & & & $\begin{array}{l}-2.613 \\
(2.973)\end{array}$ & $\begin{array}{l}-5.095 \\
(3.216)\end{array}$ \\
\hline richer_neighbor & & & $\begin{array}{c}13.08^{* * *} \\
(3.661)\end{array}$ & $\begin{array}{l}8.817^{*} \\
(5.140)\end{array}$ \\
\hline population & & & $\begin{array}{c}-0.232^{* * *} \\
(0.0632)\end{array}$ & $\begin{array}{r}-0.279^{* * *} \\
(0.0779)\end{array}$ \\
\hline chamber_size & & & $\begin{array}{l}0.167^{* * *} \\
(0.0541)\end{array}$ & $\begin{array}{l}0.228^{* * *} \\
(0.0703)\end{array}$ \\
\hline regional_elect & & & $\begin{array}{c}1.997^{* * *} \\
(0.714)\end{array}$ & $\begin{array}{c}2.220^{* * *} \\
(0.733)\end{array}$ \\
\hline Country FEs & No & No & Yes & Yes \\
\hline Observations & 1232 & 1232 & 1102 & 1102 \\
\hline
\end{tabular}

Table 11 - Vote for regionalist parties. 2SLS model explaining votes for regionalist (autonomist + secessionist) parties using the full sample. Distance is instrumented with language and distance_GDP with language_GDP. The constant term is excluded from the table for paucity. Errors clustered at the regional level. Standard errors in parentheses. $* p<0.10, * * p<0.05, * * * p<0.01$. 


\begin{tabular}{|c|c|c|c|c|}
\hline & $\begin{array}{c}(1) \\
\text { v_reg }\end{array}$ & $\begin{array}{c}(2) \\
\text { v_reg }\end{array}$ & $\begin{array}{c}(3) \\
\text { v_reg }\end{array}$ & $\begin{array}{c}(4) \\
\text { v_reg }\end{array}$ \\
\hline GDP_ratio & $\begin{array}{c}36.81^{* * *} \\
(11.11)\end{array}$ & $\begin{array}{l}-0.895 \\
(13.64)\end{array}$ & $\begin{array}{c}21.75^{* * *} \\
(5.393)\end{array}$ & $\begin{array}{l}-2.457 \\
(8.565)\end{array}$ \\
\hline distance & $\begin{array}{c}1.321^{* * *} \\
(0.443)\end{array}$ & $\begin{array}{c}3.244^{* * *} \\
(0.676)\end{array}$ & $\begin{array}{c}0.932^{* * *} \\
(0.282)\end{array}$ & $\begin{array}{c}2.141^{* * *} \\
(0.471)\end{array}$ \\
\hline language & $\begin{array}{c}48.78^{* * *} \\
(12.42)\end{array}$ & $\begin{array}{c}52.95^{* * *} \\
(10.46)\end{array}$ & $\begin{array}{c}32.43^{* * *} \\
(9.599)\end{array}$ & $\begin{array}{c}32.94^{* * *} \\
(8.459)\end{array}$ \\
\hline distance_GDP & & $\begin{array}{c}5.431^{* * *} \\
(1.533)\end{array}$ & & $\begin{array}{c}3.157^{* * *} \\
(1.098)\end{array}$ \\
\hline language_GDP & & $\begin{array}{l}76.71^{* *} \\
(30.04)\end{array}$ & & $\begin{array}{l}41.81^{*} \\
(23.64)\end{array}$ \\
\hline year & & & $\begin{array}{l}0.332^{* * *} \\
(0.0822)\end{array}$ & $\begin{array}{l}0.351^{* * *} \\
(0.0784)\end{array}$ \\
\hline has_neighbor & & & $\begin{array}{l}-1.209 \\
(4.738)\end{array}$ & $\begin{array}{l}-3.391 \\
(4.101)\end{array}$ \\
\hline richer_neighbor & & & $\begin{array}{c}18.18^{* * *} \\
(5.256)\end{array}$ & $\begin{array}{c}16.83^{* * *} \\
(5.044)\end{array}$ \\
\hline population & & & $\begin{array}{l}-0.213^{* *} \\
(0.0898)\end{array}$ & $\begin{array}{c}-0.223^{* * *} \\
(0.0820)\end{array}$ \\
\hline chamber_size & & & $\begin{array}{c}0.122^{*} \\
(0.0707)\end{array}$ & $\begin{array}{c}0.149^{* *} \\
(0.0627)\end{array}$ \\
\hline regional_election & & & $\begin{array}{c}6.811^{* * *} \\
(1.249)\end{array}$ & $\begin{array}{c}6.398^{* * *} \\
(1.314)\end{array}$ \\
\hline Country FEs & No & No & Yes & Yes \\
\hline Observations & 1232 & 1232 & 1102 & 1102 \\
\hline
\end{tabular}

Table 12 - Vote for regionalist parties. Tobit model - left censored at 0 and right censored at 100- explaining votes for regionalist (autonomist + secessionist) parties using the full sample. The constant term is excluded from the table for paucity. Errors clustered at the regional level. Standard errors in parentheses. $* p<0.10, * * p<0.05$, $* * * p<0.01$. 


\begin{tabular}{|c|c|c|c|c|}
\hline & $\begin{array}{c}(1) \\
\mathrm{v} \_r e g\end{array}$ & $\begin{array}{c}(2) \\
\text { v_reg }\end{array}$ & $\begin{array}{c}(3) \\
\text { v_reg }\end{array}$ & $\begin{array}{c}(4) \\
\mathrm{v} \_ \text {reg }\end{array}$ \\
\hline GDP_ratio & $\begin{array}{l}16.43^{* *} \\
(6.815)\end{array}$ & $\begin{array}{l}-1.313 \\
(2.770)\end{array}$ & $\begin{array}{c}12.27^{* * *} \\
(3.444)\end{array}$ & $\begin{array}{l}-2.280 \\
(5.208)\end{array}$ \\
\hline distance & $\begin{array}{l}0.805^{* *} \\
(0.310)\end{array}$ & $\begin{array}{l}0.787^{* *} \\
(0.330)\end{array}$ & $\begin{array}{c}0.718^{* * *} \\
(0.217)\end{array}$ & $\begin{array}{c}1.025^{* * *} \\
(0.273)\end{array}$ \\
\hline language & $\begin{array}{c}19.77^{* * *} \\
(7.268)\end{array}$ & $\begin{array}{c}32.48^{* * *} \\
(7.013)\end{array}$ & $\begin{array}{l}9.998^{* *} \\
(4.490)\end{array}$ & $\begin{array}{c}19.94^{* * *} \\
(6.104)\end{array}$ \\
\hline distance_GDP & & $\begin{array}{c}0.670 \\
(0.893)\end{array}$ & & $\begin{array}{l}1.457^{*} \\
(0.763)\end{array}$ \\
\hline language_GDP & & $\begin{array}{c}95.18^{* * *} \\
(22.47)\end{array}$ & & $\begin{array}{c}60.72^{* * *} \\
(18.01)\end{array}$ \\
\hline year & & & $\begin{array}{l}0.173^{* * *} \\
(0.0489)\end{array}$ & $\begin{array}{l}0.181^{* * *} \\
(0.0456)\end{array}$ \\
\hline has_neighbor & & & $\begin{array}{c}-0.0945 \\
(1.907)\end{array}$ & $\begin{array}{l}-2.943 \\
(1.913)\end{array}$ \\
\hline richer_neighbor & & & $\begin{array}{c}9.870^{* * *} \\
(3.193)\end{array}$ & $\begin{array}{c}7.579^{* * *} \\
(2.660)\end{array}$ \\
\hline population & & & $\begin{array}{c}-0.118^{* *} \\
(0.0516)\end{array}$ & $\begin{array}{c}-0.122^{\text {*** }} \\
(0.0459)\end{array}$ \\
\hline chamber_size & & & $\begin{array}{c}0.0634 \\
(0.0470)\end{array}$ & $\begin{array}{l}0.0916^{* *} \\
(0.0419)\end{array}$ \\
\hline regional_elect & & & $\begin{array}{l}1.711^{* *} \\
(0.656)\end{array}$ & $\begin{array}{l}1.683^{* *} \\
(0.647)\end{array}$ \\
\hline Country FEs & No & No & Yes & Yes \\
\hline Observations & 31732 & 31732 & 28859 & 28859 \\
\hline$R^{2}$ & 0.262 & 0.458 & 0.573 & 0.635 \\
\hline Adjusted $R^{2}$ & 0.262 & 0.458 & 0.573 & 0.634 \\
\hline
\end{tabular}

Table 13 - Vote for regionalist parties. Pooled OLS model with frequency weights as given by -the regional- population, explaining votes for regionalist (autonomist + secessionist) parties using the full sample. The constant term is excluded from the table for paucity. Errors clustered at the regional level. Standard errors in parentheses. $* p<0.10, * * p<0.05, * * * p<0.01$. 


\begin{tabular}{|c|c|c|c|c|}
\hline & $\begin{array}{l} \\
\end{array}$ & \begin{tabular}{c}
\multicolumn{2}{c}{$(2)$} \\
$\mathrm{v} \quad \mathrm{reg}$
\end{tabular} & $\begin{array}{c}(3) \\
\quad r e q\end{array}$ & $\begin{array}{c}(4) \\
\quad r e o\end{array}$ \\
\hline regional_auton & & $\begin{array}{c}29.17^{* * *} \\
(5.690)\end{array}$ & & \\
\hline ENERP & $\begin{array}{l}12.47^{* *} \\
(5.562)\end{array}$ & & & \\
\hline GDP_ratio & $\begin{array}{l}-6.688 \\
(6.009)\end{array}$ & $\begin{array}{l}-0.520 \\
(5.048)\end{array}$ & $\begin{array}{c}-1.012 \\
(4.624)\end{array}$ & $\begin{array}{c}-6.505^{*} \\
(3.642)\end{array}$ \\
\hline distance & $\begin{array}{c}1.527^{* * *} \\
(0.434)\end{array}$ & $\begin{array}{c}1.006^{* * *} \\
(0.294)\end{array}$ & $\begin{array}{c}1.139^{* * *} \\
(0.292)\end{array}$ & $\begin{array}{c}1.634^{* * *} \\
(0.263)\end{array}$ \\
\hline language & $\begin{array}{l}17.26^{* *} \\
(7.522)\end{array}$ & $\begin{array}{l}11.43^{* *} \\
(4.690)\end{array}$ & $\begin{array}{l}15.55^{* *} \\
(6.181)\end{array}$ & $\begin{array}{c}23.69^{* * *} \\
(6.836)\end{array}$ \\
\hline distance_GDP & $\begin{array}{c}1.875^{* *} \\
(0.936)\end{array}$ & $\begin{array}{c}0.969 \\
(0.662)\end{array}$ & $\begin{array}{l}1.471^{* *} \\
(0.717)\end{array}$ & $\begin{array}{c}2.321^{* * *} \\
(0.601)\end{array}$ \\
\hline language_GDP & $\begin{array}{c}30.95 \\
(24.61)\end{array}$ & $\begin{array}{c}43.61^{* * *} \\
(14.96)\end{array}$ & $\begin{array}{c}27.88 \\
(20.51)\end{array}$ & $\begin{array}{c}59.34^{* * *} \\
(13.97)\end{array}$ \\
\hline year & $\begin{array}{c}0.683^{* * *} \\
(0.248)\end{array}$ & $\begin{array}{c}-0.249^{* *} \\
(0.105)\end{array}$ & $\begin{array}{c}0.0857^{*} \\
(0.0463)\end{array}$ & $\begin{array}{l}0.118^{* * *} \\
(0.0389)\end{array}$ \\
\hline has_neighbor & $\begin{array}{l}-2.440 \\
(3.013)\end{array}$ & $\begin{array}{l}-2.175 \\
(1.561)\end{array}$ & $\begin{array}{l}-2.396 \\
(1.706)\end{array}$ & $\begin{array}{l}-4.995 \\
(3.256)\end{array}$ \\
\hline richer_neighbor & $\begin{array}{c}11.20^{* * *} \\
(3.047)\end{array}$ & $\begin{array}{c}9.898^{* * *} \\
(2.705)\end{array}$ & $\begin{array}{c}10.55^{* * *} \\
(3.379)\end{array}$ & $\begin{array}{c}8.317^{* * *} \\
(3.020)\end{array}$ \\
\hline population & $\begin{array}{l}-0.0307 \\
(0.0256)\end{array}$ & $\begin{array}{c}-0.197^{* * *} \\
(0.0522)\end{array}$ & $\begin{array}{l}-0.127^{* *} \\
(0.0492)\end{array}$ & $\begin{array}{c}-0.109^{* * *} \\
(0.0413)\end{array}$ \\
\hline regional_elect & $\begin{array}{c}6.572^{* * *} \\
(1.794)\end{array}$ & $\begin{array}{l}-0.996 \\
(0.952)\end{array}$ & $\begin{array}{c}2.244^{* * *} \\
(0.744)\end{array}$ & $\begin{array}{c}1.846^{* * *} \\
(0.497)\end{array}$ \\
\hline chamber_size & & $\begin{array}{l}0.121^{* * *} \\
(0.0419)\end{array}$ & $\begin{array}{c}0.0828^{*} \\
(0.0452)\end{array}$ & $\begin{array}{c}0.0871^{* *} \\
(0.0375)\end{array}$ \\
\hline Country FEs & Yes & Yes & Yes & Yes \\
\hline Observations & 934 & 1096 & 956 & 939 \\
\hline$R^{2}$ & - & - & 0.612 & 0.636 \\
\hline Adjusted $R^{2}$ & - & - & 0.604 & 0.628 \\
\hline
\end{tabular}

Standard errors in parentheses
${ }^{*} p<0.10,{ }^{* *} p<0.05,{ }^{* * *} p<0.01$

Table 14 - Various robustness checks. 2SLS regression instrumenting ENERP with chamber_size (1). 2SLS instrumenting regional_auton with hist_together (2). Pooled OLS excluding those regions with irredentist potential from the sample (3). Pooled OLS excluding those regions with a regional party which is also in another region from the sample (4). Errors are clustered at the regional level. The constant term is excluded from the table for paucity. Standard errors in parentheses. $* p<0.10$, $* * p<0.05, * * * p<0.01$. 


\begin{tabular}{|c|c|c|c|c|}
\hline & $\begin{array}{c}(1) \\
\mathrm{v} \_\mathrm{sec}\end{array}$ & $\begin{array}{c}(2) \\
\mathrm{v} \_ \text {sec }\end{array}$ & $\begin{array}{c}(3) \\
\mathrm{v} \_ \text {auton }\end{array}$ & $\begin{array}{c}(4) \\
\mathrm{v} \_ \text {auton }\end{array}$ \\
\hline GDP_ratio & $\begin{array}{c}4.780^{*} \\
(2.534)\end{array}$ & $\begin{array}{l}0.0519 \\
(4.454)\end{array}$ & $\begin{array}{l}8.967^{* *} \\
(4.097)\end{array}$ & $\begin{array}{l}-4.191 \\
(4.101)\end{array}$ \\
\hline distance & $\begin{array}{c}0.134 \\
(0.0947)\end{array}$ & $\begin{array}{c}0.324 \\
(0.275)\end{array}$ & $\begin{array}{c}0.550^{* * *} \\
(0.144)\end{array}$ & $\begin{array}{c}1.231^{* * *} \\
(0.231)\end{array}$ \\
\hline language & $\begin{array}{l}9.314^{* *} \\
(3.897)\end{array}$ & $\begin{array}{l}10.57^{* *} \\
(5.289)\end{array}$ & $\begin{array}{l}7.844^{*} \\
(4.265)\end{array}$ & $\begin{array}{c}10.03^{*} \\
(5.561)\end{array}$ \\
\hline distance_GDP & & $\begin{array}{c}0.481 \\
(0.600)\end{array}$ & & $\begin{array}{c}1.760^{* * *} \\
(0.649)\end{array}$ \\
\hline language_GDP & & $\begin{array}{c}13.59 \\
(17.27)\end{array}$ & & $\begin{array}{c}31.05 \\
(21.37)\end{array}$ \\
\hline year & $\begin{array}{c}0.0958^{* * *} \\
(0.0303)\end{array}$ & $\begin{array}{c}0.0976^{* * *} \\
(0.0305)\end{array}$ & $\begin{array}{c}0.0583^{*} \\
(0.0307)\end{array}$ & $\begin{array}{c}0.0611^{* *} \\
(0.0287)\end{array}$ \\
\hline has_neighbor & $\begin{array}{l}-3.143^{*} \\
(1.674)\end{array}$ & $\begin{array}{c}-3.765^{* *} \\
(1.742)\end{array}$ & $\begin{array}{c}0.405 \\
(1.920)\end{array}$ & $\begin{array}{l}-1.049 \\
(1.641)\end{array}$ \\
\hline richer_neighbor & $\begin{array}{c}9.108^{* * *} \\
(3.239)\end{array}$ & $\begin{array}{c}8.834^{* * *} \\
(3.292)\end{array}$ & $\begin{array}{c}3.721 \\
(2.377)\end{array}$ & $\begin{array}{c}2.845 \\
(2.268)\end{array}$ \\
\hline population & $\begin{array}{l}-0.0396 \\
(0.0466)\end{array}$ & $\begin{array}{l}-0.0389 \\
(0.0450)\end{array}$ & $\begin{array}{c}-0.123^{*} \\
(0.0656)\end{array}$ & $\begin{array}{c}-0.127^{* *} \\
(0.0559)\end{array}$ \\
\hline chamber_size & $\begin{array}{c}0.0518 \\
(0.0413)\end{array}$ & $\begin{array}{c}0.0586 \\
(0.0394)\end{array}$ & $\begin{array}{c}0.0303 \\
(0.0399)\end{array}$ & $\begin{array}{c}0.0491 \\
(0.0355)\end{array}$ \\
\hline regional_elect & $\begin{array}{l}0.952^{* *} \\
(0.443)\end{array}$ & $\begin{array}{l}0.886^{* *} \\
(0.438)\end{array}$ & $\begin{array}{c}1.791^{* * *} \\
(0.533)\end{array}$ & $\begin{array}{c}1.611^{* * *} \\
(0.534)\end{array}$ \\
\hline Country FEs & Yes & Yes & Yes & Yes \\
\hline Observations & 1098 & 1098 & 1072 & 1072 \\
\hline$R^{2}$ & 0.342 & 0.352 & 0.378 & 0.453 \\
\hline Adjusted $R^{2}$ & 0.331 & 0.340 & 0.368 & 0.442 \\
\hline
\end{tabular}

Table 15 - Vote for secessionist and autonomist parties. Standard errors in parentheses. Pooled OLS model explaining votes for secessionist parties, using the full sample, columns (1), (2), and for autonomist parties, columns (3), (4). Errors are clustered at the regional level. The constant term is excluded from the table for paucity. Standard errors in parentheses. $* p<0.10, * * p<0.05, * * * p<0.01$. 


\subsection{Figure}

Figure 2 - Net wealth distribution in surveyed EMU countries $(\mathrm{ECB}, 2013)$

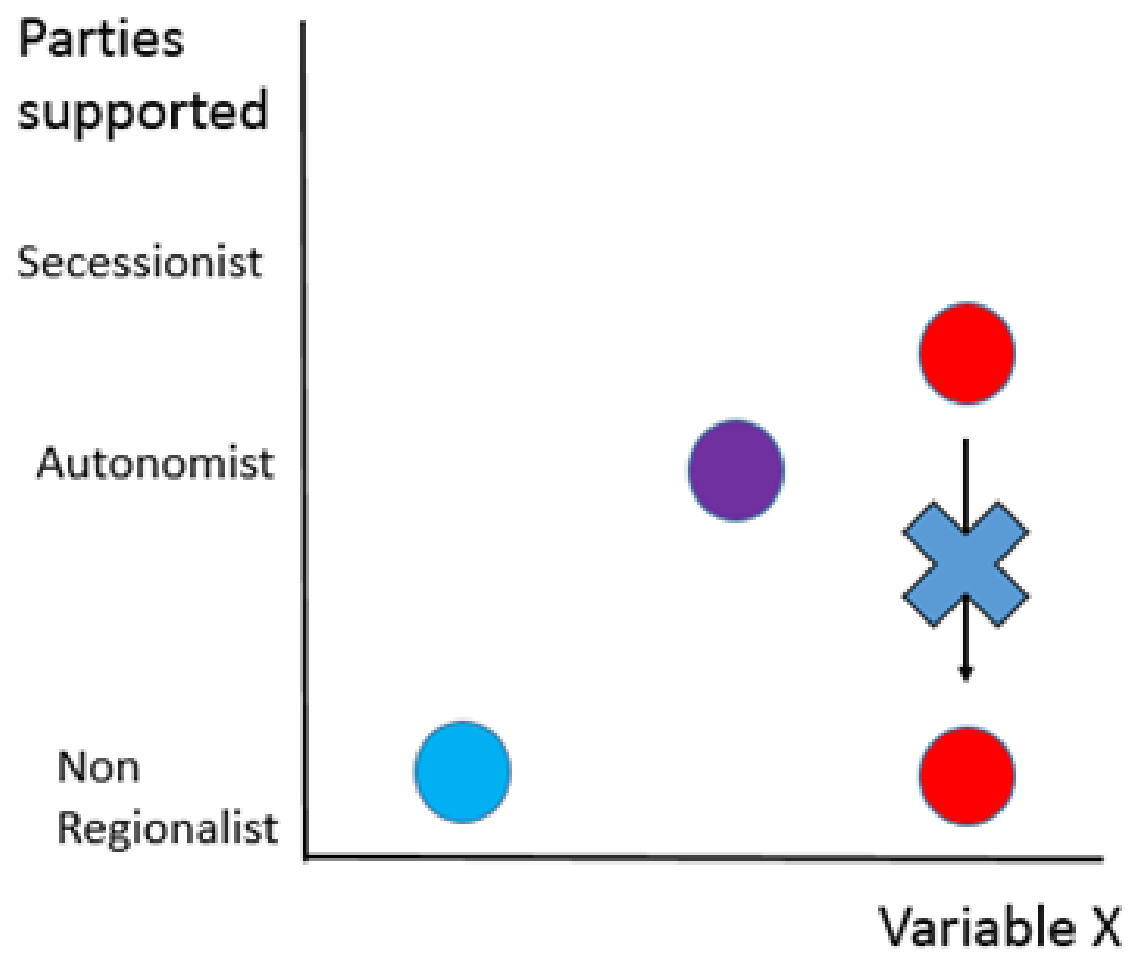

Figure 3 - Hypothetical support for different parties as a function of a variable $X$. The crossed arrow illustrates what we would be comparing — and should not compare - if we use the vote for autonomist parties as dependent variable.

\section{References}

Alesina, Alberto and Enrico Spolaore (1997), "On the number and size of nations." The Quarterly Journal of Economics, 112, 1027-1056.

Assembly of European Regions (1996), "Declaration of Regionalism in Europe."

Bloom, William (1993), Personal identity, national identity and international relations, volume 9. Cambridge University Press.

Bolton, Patrick and Gerard Roland (1997), "The breakup of nations: a political economy analysis." The Quarterly Journal of Economics, 112, 1057-1090.

Brancati, Dawn (2014), "Another great illusion: the advancement of separatism through economic integration." Political Science Research and Methods, 2, 69-95.

De Winter, Lieven, L De Winter, and H Türsan (1998), "A comparative analysis of the electoral, office and policy success of ethnoregionalist parties." Regionalist Parties in Western Europe, 204-247. 
Della Porta, D., F. O'Connor, M. Portos, and A Subirats (2017), Referendums from Below: Social movements and direct democracy in the neoliberal crisis. Bristol: Policy Press.

Desmet, Klaus, Michel Le Breton, Ignacio Ortuño-Ortín, and Shlomo Weber (2011), "The stability and breakup of nations: a quantitative analysis." Journal of Economic Growth, 16, 183.

Fearon, James D and Pieter Van Houten (2002), "The politicization of cultural and economic difference." In Fifth meeting of the Laboratory in Comparative Ethnic Processes. Stanford University, May.

Gordin, Jorge P (2001), "The electoral fate of ethnoregionalist parties in Western Europe: A Boolean test of extant explanations." Scandinavian Political Studies, 24, 149-170.

Hale, Henry E (2008), The foundations of ethnic politics: separatism of states and nations in Eurasia and the world. Cambridge University Press Cambridge.

Hooghe, Liesbet, Gary N Marks, Arjan H Schakel, et al. (2010), The rise of regional authority: A comparative study of 42 democracies. Routledge.

Horowitz, Donald L (1981), "Patterns of ethnic separatism." Comparative Studies in Society and History, 23, 165-195.

Jolly, Seth (2006), "A Europe of regions? Regional integration, sub-national mobilization and the optimal size of states." Durham, NC: Duke University.

Keating, Michael (2004), "European integration and the nationalities question." Politics \&f society, 32, 367-388.

Laakso, Markku and Rein Taagepera (1979), "Effective number of parties: a measure with application to West Europe." Comparative political studies, 12, 3-27.

Laitin, David D (2007), Nations, states, and violence. Oxford University Press.

Lewis, M Paul and F Gary (2013), "Simons, and charles d. fennig (eds.). 2013. ethnologue: Languages of the world, dallas, texas: Sil international." Online version: http://www. ethnologue. com.

Massetti, Emanuele (2009), "Explaining regionalist party positioning in a multidimensional ideological space: A framework for analysis." Regional and Federal Studies, 19, 501-531.

Massetti, Emanuele and Arjan H Schakel (2016), "Between autonomy and secession: Decentralization and regionalist party ideological radicalism." Party Politics, 22, 59-79.

Medeiros, Mike, Jean-Philippe Gauvin, and Chris Chhim (2015), "Refining vote choice in an ethno-regionalist context: Three-dimensional ideological voting in Catalonia and Quebec." Electoral Studies, 40, 14-22.

Moreno, Luis (1995), "Multiple ethnoterritorial concurrence in Spain." Nationalism and Ethnic Politics, 1, 11-32. 
Muñoz, Jordi and Raül Tormos (2015), "Economic expectations and support for secession in Catalonia: between causality and rationalization." European Political Science Review, 7, 315-341.

Nordsieck, Wolfram (2015), "Parties and elections in Europe." Parties and Elections.

Parekh, Bhikhu (1995), "The concept of national identity." Journal of Ethnic and Migration Studies, 21, 255-268.

Riera, Pedro (2014), "Nationalist parties and voting in the balearic islands." Unpublished manuscript.

Sorens, Jason (2004), "Globalization, secessionism, and autonomy." Electoral Studies, 23, 727-752.

Sorens, Jason (2005), "The cross-sectional determinants of secessionism in advanced democracies." Comparative Political Studies, 38, 304-326.

Sorens, Jason (2008), "Regionalists against secession: the political economy of territory in advanced democracies." Nationalism and Ethnic Politics, 14, 325-360.

Sorens, Jason (2012), Secessionism: Identity, interest, and strategy. McGill-Queen's Press-MQUP.

Spinner-Halev, Jeff and Elizabeth Theiss-Morse (2003), "National identity and selfesteem." Perspectives on politics, 1, 515-532.

Taagepera, Rein and Matthew Soberg Shugart (1989), Seats and votes: The effects and determinants of electoral systems. Yale University Press.

Van Houten, Pieter Jacob (2000), Regional assertivness in Western Europe political constraints and the role of party competition. Ph.D. thesis, University of Chicago, Dept. of Political Science. 